\title{
The lure of the visual: Multimodality, simplification, and performance measurement visualizations in a megaproject
}

DOI:

10.1016/j.aos.2021.101296

\section{Document Version}

Accepted author manuscript

Link to publication record in Manchester Research Explorer

\section{Citation for published version (APA):}

Ronzani, M., \& Gatzweiler, M. K. (2022). The lure of the visual: Multimodality, simplification, and performance measurement visualizations in a megaproject. Accounting, Organizations and Society, 97, 1-19. [101296]. https://doi.org/10.1016/j.aos.2021.101296

\section{Published in:}

Accounting, Organizations and Society

\section{Citing this paper}

Please note that where the full-text provided on Manchester Research Explorer is the Author Accepted Manuscript or Proof version this may differ from the final Published version. If citing, it is advised that you check and use the publisher's definitive version.

\section{General rights}

Copyright and moral rights for the publications made accessible in the Research Explorer are retained by the authors and/or other copyright owners and it is a condition of accessing publications that users recognise and abide by the legal requirements associated with these rights.

\section{Takedown policy}

If you believe that this document breaches copyright please refer to the University of Manchester's Takedown Procedures [http://man.ac.uk/04Y6Bo] or contact uml.scholarlycommunications@manchester.ac.uk providing relevant details, so we can investigate your claim.

\section{OPEN ACCESS}




\title{
The lure of the visual: \\ Multimodality, simplification, and performance measurement visualizations in a megaproject
}

\author{
Matteo Ronzani \\ Alliance Manchester Business School \\ matteo.ronzani@manchester.ac.uk (corresponding author)
}

Marian Konstantin Gatzweiler

The University of Edinburgh Business School

marian.gatzweiler@ed.ac.uk

\begin{abstract}
This study explores the risks and consequences of the reliance on visualizations in performance measurement for the sake of the simplicity and actionability of performance information. Despite the mounting interest in the visual aspects of accounting, little is known about what can happen when visuals are so embedded in organizations that they become a key semiotic resource for communicating performance measurement information. Theoretically, we draw from multimodality research to unpack how different semiotic modes (i.e., visuals, text, and numbers) interact in organizational meaning-making. To explore these issues, we conducted a study of the visual practices of one of the largest infrastructure megaprojects in the UK. The paper makes two contributions. Our first contribution consists of qualifying what we call the lure of the visual: A seemingly paradoxical process whereby the increasing ubiquity and reliance on visuals in an organization induces the trivialization of performance measurement visualizations and limits the communicative opportunities they offer to users. In so doing, we offer a substantive qualification of the risks and consequences of visual approaches to performance measurement. Our second contribution to the accounting literature is the theorization of how multiple semiotic modes can interact in performance measurement. We theorize three multimodal relationships between visuals, numbers, and text that shed new light on how performance measurement artifacts generate meaning in organizations.
\end{abstract}

Keywords: Performance Measurement; Visualization; Multimodality; Simplification; Megaproject.

Acknowledgments: The first author would like to acknowledge the support of the Economic and Social Research Council who funded the data collection for this research (ES/M500380/1 ESRC Impact Acceleration Account 2014 - University of Edinburgh). Special thanks go to David Cooper, Sven Modell, and Paolo Quattrone for their feedback and constant support throughout multiple iterations of this manuscript. We also wish to acknowledge comments and suggestions by Justyna Bandola-Gill, Christos Begkos, Chris Carter, Luciana D'Adderio, Sotiria Grek, Shaul Hayoun, Markus Höllerer, Christopher Humphrey, Jakov Jandrić, Ingrid Jeacle, Dennis Jancsary, Martin Kornberger, Gordon Masterton, Jan Mouritsen, Andrea Mennicken, Yuval Millo, Brendan O’Dwyer, Neil Pollock, Francois-Regis Puyou, John Roberts, Robert Scapens, Ben Sila, Jonathan Tweedie, and ChunLei Yang. We are also grateful to the participants of the departmental seminars where this study has been presented: Cambridge Judge Business School; The University of Edinburgh Business School; Alliance Manchester Business School; Adam Smith Business School; St Andrews School of Management; NHH Norwegian School of Economics. Last but not least, we wish to thank three anonymous Referees and the Editor, Wai Fong Chua, for invaluable suggestions and guidance. 


\section{Introduction}

Visualizations to measure performance have become ubiquitous in organizations and society. The availability of quantitative data and performance information in organizations has been closely followed by a burgeoning of visual artifacts and technologies that seek to transform these data into understandable and actionable information (Espeland \& Stevens, 2008; Pollock \& D’Adderio, 2012). The visualization of complex datasets is frequently regarded as a possible panacea for many interpretative and communicative issues that affect organizations (Kinsella, 2019; Isset \& Hicks, 2017; Tufte, 2001). A compelling visual display of quantitative information is often said to provide improved legibility, the perception of novel relations in complex datasets, and the rendering of numerical values visible at a glance, in ways that accounting spreadsheets or data tables cannot (Eppler \& Platts, 2009; Cardinaels, 2008; Cheng \& Humphreys, 2012). The ubiquity of easily accessible technologies for data analytics that give form to otherwise amorphous data have further propelled the dissemination of performance visualizations (Aral, 2013; Berinato, 2016). The focus on the visual features of performance data displays is frequently linked to efforts to develop user-friendly interfaces that render numerical data captivating to users for their simplicity, polish, and clarity (Espeland \& Stevens, 2008; Pollock \& D’Adderio, 2012; Jack, 2013).

Performance measurement has been affected by such trends, becoming more visual and reliant on dashboards, scorecards, and risk and ranking visualizations ( $\mathrm{Qu} \&$ Cooper, 2011; Pollock \& D'Adderio, 2012; Busco \& Quattrone, 2015; Cooper, Ezzamel, \& Qu, 2017; Themsen \& Skærbæk, 2018; Jordan, Mitterhofer, \& Jørgensen, 2018). The popularity of visual tools has made the users of performance measures accustomed to the consumption and appropriation of these figures in various organizational contexts (Graham, 2008; Mouritsen, 2011; Manochin, Brignall, Lowe, \& Howell, 2011; Martinez \& Cooper, 2019; Begkos \& Antonopoulou, 2020). Despite the mounting interest in the visual aspects of accounting (Davison, 2015), little is known about the risks and consequences associated with the increasing reliance on visual approaches to performance measurement in organizations. Considering the popularity of performance measurement visualizations and the academic and managerial discourses surrounding the virtues of their simplicity, developing a theoretical understanding of how the reliance on visualizations affects how performance measurement generates meaning in organizations is of timely relevance.

To address these issues, we build on and expand recent developments in organizational scholarship on multimodality that investigate how different semiotic modes (e.g., visuals, text, 
or numbers) generate meaning in organizations (e.g., Meyer, Jancsary, Höllerer, \& Boxenbaum, 2018; Höllerer, van Leeuwen, Jancsary, Meyer, Anderseen, \& Vaara, 2019; Knight \& Tsoukas, 2019). Multimodality research seeks to explain how different semiotic modes enable and constrain meaning-making and how they interact and interfere with each other in organizations (Meyer et al., 2018; Lefsrud, Graves, \& Phillips, 2020). While accounting scholarship has explored issues of representation and visualization in depth (e.g., Hines, 1988; Tinker, 1991; Chua, 1995; Mouritsen, 2011; see Davison, 2015 for a review), multimodality offers further nuance by distinguishing between different semiotic modes that make up accounting representations, especially in relation to how they generate meaning in virtue of their distinct semiotic characteristics. We argue that including multimodality in the theoretical toolkit of accounting scholars allows exploring these issues in granular detail and in a novel manner. From this perspective, communication is a multimodal accomplishment that can be understood by focusing on how the semiotic resources available in organizational artifacts (e.g., text, numbers, and visuals) influence one another and the viewers' interpretations rather than developing a series of interconnected monomodal descriptions (Jancsary, Meyer, Höllerer, \& Boxenbaum, 2018). However, accounting and multimodality scholars have not explored what happens when one mode - such as the visual mode - becomes a key semiotic resource in performance measurement for the sake of concerns with the simplicity and understandability of performance information. Hence, we explore the following research question: What happens if reliance on the visual mode increases relative to other semiotic modes - such as numbers and text - in performance measurement, and what are some of the resulting risks and consequences?

To explore these theoretical concerns, the paper draws on an empirical study of the visual practices in one of the largest infrastructure megaprojects in the UK, which we anonymize as MegaRail. We follow a change effort requested by the megaproject leadership to simplify the outputs of the organization's performance measurement function through the systematic use of visualizations. To do so, we focus on how a KPI visualization particular to the organization came about, how it became practiced, and its effects on performance measurement. We develop a series of snapshots that illustrate how distinct multimodal relations among numbers, visuals, and text emerged and gained conventional currency in the organization. The joint analysis of artifacts, interviews, documents, and observational insights allows us to qualify the effects of the commitment to visualizations in performance measurement in the organization. 
Our study makes two contributions to the literature on the visual in accounting and performance measurement. First, it qualifies what we call the lure of the visual: A seemingly paradoxical process whereby the increasing ubiquity and reliance on visuals in an organization induces the trivialization of performance measurement visualizations and limits the communicative opportunities they offer to users. By unpacking the lure of the visual, we provide a substantive qualification the risks and consequences of visual approaches to performance measurement that are undertheorized in the existing scholarship, which has so far foregrounded their enabling potential (Dambrin \& Robson, 2011; Qu \& Cooper, 2011; Free \& Qu, 2011; Pollock \& D’Adderio, 2012; Busco \& Quattrone, 2015; Martinez \& Cooper, 2019). Our theorization of the lure of the visual also challenges the prescriptions of functionalist and experimental proponents of visual approaches to accounting and performance measurement (e.g., Lipe \& Salterio, 2000, 2002; Cardinaels, 2008; Cheng \& Humphreys, 2012; Kinsella, 2019) who contend that visual artifacts have inherently enabling properties.

Our second contribution to the accounting literature on the visual is a theorization of how multiple semiotic modes can interact in performance measurement, affecting how performance measurement artifacts generate meaning in virtue of the semiotic resources they deploy. Such an approach expands extant debates that thus far have privileged monomodal accounts of meaning-making in accounting (e.g., Boland, 1993; Macintosh, 2002; Lorino, Mourey, \& Schmidt, 2017) or have isolated the analysis of visual meaning from its broader communicative context (e.g., Preston, Wright, \& Young, 1996; Graves, Flesher, \& Jordan, 1996; Davison, 2010, 2014). Based on our findings, we identify three multimodal relationships between the visual, numerical, and textual semiotic modes: Imbuement, juxtaposition, and eclipsing. By theorizing these relationships, we show that multimodal mixes that combine a wealth of different semiotic resources can spark curiosity and sustain interactions with performance reports, whereas simple, clean, and polished reports may deter engagement. This adds further nuance to studies that have problematized how the consolidation of visual approaches to accounting and performance measurement may prevent these artifacts from prompting inquiry and engagement (Mouritsen, 2011; Busco \& Quattrone, 2015; Quattrone, 2017; Arjaliès \& Bansal, 2018). Our analysis shows that reports where the visual mode is thoroughly regulated may preclude artifacts from invoking tensions and generating critical interactions.

Our study proceeds as follows. In the next section, we review the literature on accounting and performance measurement visualizations. Section 3 develops insights from research on multimodality to investigate how multiple semiotic modes of communication 
generate meaning in performance measurement. In section 4, we present the research methodology and our case setting. In section 5, we present our findings, showing how performance measurement visualizations generate meanings in MegaRail. Lastly, in section 6, we discuss the theoretical implications of our findings for research on the visual in accounting and outline our contributions.

\section{The appetite for simple performance measurement visualizations}

Technological advancements in ERPs, Business Intelligence, and Big-Data Analytics have affected how performance measurement information is extracted from a myriad of data sources and how it is visualized and communicated inside organizations (Jack, 2013; Quattrone, 2017). These advancements have not only affected the quantity of performance data that can be visualized with relative ease, but also the qualities of the visualizations that can be produced, which are seen as increasingly interactive, customizable, and high-definition (Bandola-Gill, Grek, \& Ronzani, 2021). More and more layers of information processing are occurring before the performance figures are communicated in visual formats to their users, who may be detached from the processes involved in their production (Graham, 2008; Quattrone, 2016). The layouts of performance measurement visualizations are increasingly designed to be simple for the sake of aspirational notions of understandability and actionability, as attributes such as clarity and parsimony are expected to facilitate the interpretation of calculative technologies (Espeland \& Stevens, 2008; Pollock \& D'Adderio, 2012). These shifts are also propelled by academic discourses that accentuate the communicative virtues of visual simplicity (e.g., Tufte, 2001; Aral, 2013; Berinato, 2016) and are frequently accompanied by the assumption that stripping complexity from numbers (Ashkenas, 2007; Isset \& Hicks, 2017) and accounting figures (Chambers, 1999; Kinsella, 2019) is essential to generate communicable insight. The focus on visual simplification further conceals the messiness of the numbers, gaps, and approximations that characterize the production of performance measures (Dambrin \& Robson, 2011).

Conceptually, no account or numerical representation is complete or unaffected by value-laden simplifications (e.g., Hines, 1988; Tinker, 1991; Chua, 1995). However, visual simplifications may offer communicative possibilities that are not found in the original information. Scholars have highlighted how the simplifications required to produce accounts could be enabling and "effectively communicate and engage the user in a performative exercise" (Quattrone, 2009, p.109), thereby facilitating the spread of accounting ideas (Thompson, 1991, 1998; Suzuki, 2003). The simplification of accounting information through 
visual artifacts highlights how calculations are often supported by visuals that influence the production, assessment, and financialization of value (Preston et al., 1996; Arjaliès \& Bansal, 2018; Mennicken \& Espeland, 2019). Images are deployed in annual reports to convey intangibles - such as intellectual, symbolic, and social assets - that accounting tools cannot conventionally capture and convey multi-faceted meanings that interweave information and impression management (Davison, 2010, 2014), allowing the engagement of non-expert audiences (Graves et al., 1996; Preston \& Young, 2000; Justesen \& Mouritsen, 2009).

The proliferation of visuals in accounting is also boosted by the expectation that people can engage with them as visual literacy is becoming "a matter of survival, especially in the workplace" (Kress \& van Leeuwen, 2006, p.3). Recent years have witnessed the burgeoning of technologies (e.g., Tableau) that can produce performance dashboards that seek to make "analyzing data fast and easy, beautiful and useful [...] and help people see and understand data" (Tableau, 2020). This simplification and interactivity rhetoric is affecting how performance visualizations are produced (Bandola-Gill et al., 2021). The popularity of visual displays of performance information is both driving and attending to a craving for simple and user-friendly visualizations in organizations.

The users of performance measurement visualizations "want them to be not only errorless but also compelling, elegant, and even beautiful" (Espeland \& Stevens, 2008, p.422); in this area, beauty and simplicity tend to be seen as synonymous (Jack, 2013). Indeed, these visualizations should come with a warning as the trend towards simpler and simpler visualizations that mobilize larger and larger datasets may be at odds with the interdependencies that are recognized in contemporary organizing. In this sense, the simplifying power of visualizations is such that the "complex knowledge society [becomes] suddenly a handful of numerical representations and a narrative" (Mouritsen, 2011, p.233). We argue that the academic discourse surrounding the visuals' capacity to compress information, capture interconnections, and mitigate information overload (e.g., Tufte, 2001; Eppler \& Platts, 2009; Isset \& Hicks, 2017; Kinsella, 2019) is propelled by experimental advocates of visual approaches to performance measurement.

\section{Visual simplicity and decontextualized performance}

One issue inherent in simple performance visualizations is the risk that they come to be seen as decontextualized from the norms and conventions that shape their use in organizations. This matter seems especially problematic regarding ready-made or automatically generated layouts (Tufte, 2001) and accounting templates (Graham, 2008; Quattrone, 2016, 2017). Assumptions 
about the decontextualized influence of visuals are common in experimental accounting research. Popular behavioral psychology findings indicate the pervasive limitations of numerical literacy and highlight the comparative advantages of visual/graphical presentations over numerical formats (e.g., Kahneman, 2011). The ostensibly lower cognitive burden placed upon users by visuals vis-à-vis numbers is reflected in the trend towards simplification in the visualization of performance information.

Experimental accounting research indicates that cost presentation formats and the visual arrangement of indicators affect evaluation and that graphical data are influential in facilitating the memorization of data trends (e.g., Beattie \& Jones, 1992). Cardinaels (2008) finds that managers with basic accounting skills tend to be "better" supported in their decisions by simpler graphical representations, while experts tend to perform "better" using detailed cost information in tabular formats, and they are less susceptible to be affected by "inappropriate" presentation formats (Vera-Muñoz, Kinney, \& Bonner, 2001). Experimentalists also maintain that graphical formats may improve the accuracy of forecast judgments compared to purely numerical or numerical and graphical layouts (Desanctis \& Jarvenpaa, 1989). Scholars have also shown that individual measures in a Balanced Scorecard (BSC) tend to be systematically underweighted in performance evaluation (Lipe \& Salterio, 2000, 2002) and that changes in the design of a BSC may increase the weight assigned to non-financial indicators (Cardinaels \& van Veen-Dirks, 2010). Similarly, it has been claimed that Strategy Maps can improve the perception of ostensibly causal links among organizational objectives versus their presentation in BSC format (Cheng \& Humphreys, 2012).

These studies emphasize the importance of the visual arrangement of graphs and performance measures by monitoring their use in "laboratory conditions," assuming decontextualized notions of good and bad performance. Accordingly, experimental studies tend to ignore the organizational features of the contexts where visualizations are practiced and that they frequently become useful through recombination, patchwork intervention, and unfolding processes of fabrication (Preston, Cooper, \& Coombs, 1992; Chua, 1995; Briers \& Chua, 2001; Martinez \& Cooper, 2019; Begkos \& Antonopoulou, 2020), often achieving outcomes that differ from their intended goal (Busco \& Quattrone, 2015). Indeed, disembedded visualizations and calculative practices may have counterproductive effects if key actors reject, resist, or deconstruct what these technologies stand for, as their alleged power does not manifest itself in a vacuum (Boedker, Chong, \& Mouritsen, 2019).

\section{Visualizations in organizational practices}


Accounting research within organizations has explored how visualizations unfold in practice and construct visibilities in diverse settings (Chua, 1995; Bloomfield \& Vurdubakis, 1997). A stream of studies has highlighted how visualizations influence the conduct of conduct, namely, accounting's capacity to shape the preferences of those whom it informs and to create the possibility of actors being controlled by others (Hoskin \& Macve, 1986). This literature illustrates how performance visualizations are constantly adapted during interactions (Themsen $\&$ Skærbæk, 2018) and become useful by embodying programmatic ideals related to efficiency, quantification, and rationality (Andon, Baxter, \& Chua, 2015; Chakhovich \& McGoun, 2016; Jordan et al., 2018; Mazmanian \& Beckman, 2018). Accounting interventions in organizations can also affect the subjective gaze that individuals and groups cast on themselves, others, and organizational phenomena (Chua \& Degeling, 1993; Cooper \& Ezzamel, 2013). For example, Red-Amber-Green color-coding can become so entwined with subjective narratives of performance improvement as to enact notions of self-regulation (Manochin et al., 2011).

The organizing force of visualizations also depends on how generic templates become contextually situated in meaning-making (Lorino et al., 2017) and sensemaking processes (Gatzweiler \& Ronzani, 2019). Scholars argue that the BSC becomes meaningful through adaptations and rituals of engagement (Busco \& Quattrone, 2015). The simplicity of the BSC can render "interactions visible, imposing order, and limiting externalities" (Cooper et al., 2017, p.1012), thereby facilitating communication and crystallizing vague concepts into persuasive forms (Qu \& Cooper, 2011; Free \& Qu, 2011). Additionally, simple ranking visualizations can shape markets if key actors perceive them as legitimate and are deeply ingrained in professional networks (Pollock \& D'Adderio, 2012). Notably, the visualizations' power depends not only on "cold" cognitive calculations but also on how they may create an emotional attachment to specific issues (Boedker \& Chua, 2013; Baxter, Carlsson-Wall, Chua, \& Kraus, 2019).

Extant literature has thus far privileged the investigation of the enabling power of performance measurement visualizations, foregrounding how they may engage actors through recombination, fabrication, and the shaping of domains. However, less is known about the risks and consequences of visualizations that become deeply embedded in organizational setting. This paper suggests that, to explicate these risks and consequences, it is insightful to explore what happens when reliance on visuals in performance measurement becomes prevalent in organizations. Considering the ubiquity that simple visualizations are acquiring in performance 
measurement, we argue that this issue deserves further exploration. To attend to these theoretical concerns, we mobilize insights from organizational literature on multimodality.

\section{Theoretical background on multimodality}

Visual artifacts offer a material site to investigate how meanings are communicated, reified, perpetuated, or resisted in organizations. Performance measurement visualizations are part of the interlinked systems of signification that make the communicative construction of social reality possible (see Luckmann, 2006) as visuals, together with text, speech, numbers, and

other forms of symbolic interactions are not just [...] expressions or reflections of inner thoughts or collective intentions, but [are] formative of institutional reality (Cornelissen, Durand, Fiss, Lammers, \& Vaara, 2015, p.11).

In what follows, we articulate some theoretical resources to empirically explore how visuals, numbers, and text interact in performance measurement in organizations. We seek to investigate what happens when performance measurement visualizations become written into the eye (Gagliardi, 2006) of organizational actors - namely when visualizations are so embedded in an organization's reality that they become central to the actors' ways-of-seeing what they encounter.

\section{Multiple semiotic modes of communication in organizations}

Scholars have long stressed the notion that verbal language is a key sign system in organizations, highlighting its importance as a repository for meaning making, constitutive of social interactions and organizational order (Berger \& Luckmann, 1967). Advances in rhetorical (e.g., Green, 2004; Suddaby \& Greenwood, 2015) and communicative institutionalism (e.g., Ashcraft, Kuhn, \& Coreen, 2009; Cornelissen et al., 2015) have broadened an understanding of the way social knowledge depends on a wider set of sign systems beyond verbal language. Multimodality scholars who seek to explore the interaction of multiple sign systems in generating meaning in organizations have recently expanded this agenda (e.g., Jancsary et al., 2018; Barberá-Tomás et al., 2019; Höllerer et al., 2019). Building on the research tradition of social semiotics (e.g., Halliday, 1978), multimodality scholars emphasize how meaning is a supra-individual construct accomplished through multiple modes of communication (e.g., text and visuals), which are "socially shaped and culturally given semiotic resource[s] for making meaning” (Kress, 2009, p.79).

Monomodal communication is seldom the norm in contemporary organizations (Kress \& Van Leeuwen, 2006; Kress, 2009). Multimodality is prevalent in most established genres of 
accounting and organizational communication, such as annual reports, performance dashboards, and PowerPoint presentations - communications that rely primarily on the visual (e.g., graphs, images, and colors), textual (e.g., titles, sentences, and paragraphs), and numerical modes (e.g., numbers, formulas, and indicators). From a multimodality perspective, communication is sustained by interactions between semiotic modes, which generate a

dynamic, interactive process of manipulating symbols toward the creation, maintenance, destruction, and/or transformation of meanings, which are axial - not peripheral - to organizational existence and organizing phenomena (Ashcraft et al., 2009, p.22).

Studying meaning-making requires considering how the semiotic resources available in multimodal artifacts influence one another and the viewers' interpretations rather than developing a series of interconnected monomodal descriptions. That is because multimodal communication depends on the integration of semiotic modes, all of which are, in principle, of equal value: As the term integration suggests, semiotic modes are theoretical abstractions that become significant through their interaction in acts of meaning-making (Kress, 2009). From this perspective, an artifact that relies on multiple semiotic modes can be referred to as a multimodal mix (Höllerer et al., 2019), which is a key unit of multimodal analysis.

Although the issue of representation has been a key concern of interdisciplinary accounting scholars (e.g., Tinker, 1991; Thompson, 1991; Chua, 1995; Mouritsen, 2011), the semiotic focus of multimodality allows exploring in granular detail how different sign systems and varied types of accounting representations generate meaning in organizations. Accounting approaches concerned with meaning-making tend to implicitly adopt a monomodal approach (e.g., Boland, 1993; Macintosh, 2002; Lorino et al., 2017; Hayoun, 2019) or privilege the decoding of visual meaning in isolation from other modes (e.g., Graves et al., 1996; Preston et al., 1996; Preston \& Young, 2000; Davison, 2010, 2014), such as numbers and text, that are of pivotal importance for accounting. We argue that multimodality is apt for investigating how artifacts that rely on various semiotic resources generate meaning and provide compelling accounts of visual practices in organizations.

\section{Unpacking the missing links between the visual, numerical, and textual semiotic modes}

Organizational research on multimodality has paid particular attention to how the textual and visual modes interact, frequently by contrasting their operation (Meyer et al., 2018; Höllerer et al., 2019; Lefsrud et al., 2020). Research has highlighted that the textual mode structures meaning primarily in a linear, additive manner because it is governed by a vocabulary and a 
syntax (Höllerer et al., 2019; Knight \& Tsoukas, 2019). For this reason, the textual mode lends itself to the development of formal arguments and the creation of abstract and elaborate narratives (Meyer et al., 2018). On the contrary, the absence of a "grammar" that regulates the use of visuals makes them more ambiguous, polysemic, and dependent to a larger degree on the legitimacy and social regulation they possess in context (Puyou \& Quattrone, 2018; Knight \& Tsoukas, 2019; Lefsrud et al. 2020). Further, since visuals are initially experienced holistically and then the components are parsed, they can intuitively capture spatial relations and convey complex relationships at a glance (Meyer et al., 2018). In light of this, text can support images with specification by establishing complementarity relationships whereby textual components disambiguate visual meaning or provide context (e.g., museum tags “explaining" paintings), or words can cue what is absent from an image (Lefsrud et al., 2020).

Given our focus on performance measurement artifacts, we problematize how the visual, numerical, and textual modes interact in specific layouts (i.e., the possibilities of putting things in space in a meaningful way). In so doing, we expand the gamut of multimodality to account for the interaction between the thus far neglected numerical mode and the visual and textual semiotic modes, while avoiding the reification of meaning (i.e., treating the meaningmaking potential of one semiotic mode as separate) in the study of performance measurement. Qualifying how numbers interact with other semiotic modes is central for accounting research to understand how visual approaches to performance measurement have become ubiquitous and why they have acquired prominence in recent years.

\section{Methodology}

To explore the risks and consequences of the practice of performance measurement visualizations, we conducted a qualitative case study. In order to understand what visuals "do", an exploration of how visualizations shape meaning making requires detailed insights into the construction of local meanings under in vivo conditions and an observation of interactions (Höllerer et al., 2019). Case study research offers the spatial and temporal depth required to investigate the way multiple semiotic modes become a locus of interaction when organizational actors work out ways of understanding and using specific artifacts (Höllerer et al., 2019). It is critical in the development of case studies to select "phenomena in which the context is crucial because the context affects the phenomena being studied (and where the phenomena may also interact with and influence its context)" (Cooper \& Morgan, 2008, p.160). Accordingly, we selected a setting in which performance measurement visualizations are central for actors to act upon their environment. 
The study was conducted at the Program Controls department of a megaproject that we anonymize as MegaRail. MegaRail is a multibillion pounds rail infrastructure megaproject in the UK that employed thousands of people at peak, required the development of complex and technologically advanced tunneling operations, and the realization of several new stations in densely populated areas. The delivery of MegaRail is over time and over budget, like the overwhelming majority of infrastructure megaprojects (Flyvbjerg, 2014). Common complications in megaproject delivery are identified in long planning horizons, complex interfaces, non-standard technology, and budget and contingencies tend to be inaccurate and vague due to the scale, size, and the political and technical complexity of these endeavors (Flyvbjerg, 2014).

In settings such as megaprojects, various stakeholders (e.g., control managers, executive directors, board members, sponsor organizations, and the Government) produce large amounts of reporting information. The amount of reporting information produced in megaprojects increases the risk of information overload, and visualizations have become key in dealing with these issues as tools that can simplify information (Quattrone, 2017). Crucially for our study, infrastructure megaprojects are organizations characterized by visual tools for design, planning, and reporting that are symbolic manifestations of the visual practices of engineers (Ferguson, 1999), project managers (Eppler \& Platts, 2009), and accountants (Themsen \& Skærbæk, 2018). For instance, in the engineering profession, experts are formally trained to think and express themselves visually (Ferguson, 1999), increasing the credibility and seriousness associated with visual communications and reducing the resistance towards visual practices. This is increasingly applicable to accounting and performance measurement (Jack, 2013; Davison, 2015; Quattrone, 2017). Considering these factors, the organization of infrastructure megaprojects is suitable to explore pertinent organizational challenges surrounding the communicative potential of performance measurement artifacts.

\section{Data collection}

To gain an in-depth understanding of the case, the first author engaged in fieldwork from January 2017 to March 2018. The data for this study included (1) 42 interviews with 30 participants from MegaRail, ranging from control engineers and management accountants to board members; (2) participant observation conducted at MegaRail headquarters and on various construction sites; (3) visual material produced on site, with a focus on visualizations contained in reports, performance dashboards, and PowerPoint presentations; (4) publicly available information, such as newspaper articles and documents. 
The data collection unfolded in three phases. First, a pilot study with six participants was conducted to develop a general sense of the challenges that characterize performance reporting in MegaRail. The pilot was essential to establishing rapport with key participants and offered such insights as the structure and cadence of the reporting cycle, the reporting and organizational hierarchy, identification of and reporting to stakeholders and sponsors, and the main challenges of program delivery. Three performance measurement visualizations from the pilot that were investigated in detail emerged as particularly influential: the "worm diagram," the program dashboard, and the board report summary. Second, the interview protocol was developed based upon the pilot study, and 30 participants were interviewed. Third, after the first set of interviews, the first author returned to collect further data to see what had changed and what remained stable over time and to test our emerging understanding of the case. Thus, 12 follow-up interviews were conducted with a narrower scope and focusing on specific features of performance measurement visualizations.

Most of the follow-up interviews were conducted with participants from the Program Controls department because they oversee the production of the performance reports. Most participants have an engineering background and several of them hold management accounting certifications. The schedule of interviews is detailed in Table 1 below.

\section{[Insert Table 1 about here]}

In both the interviews and the follow-ups, the participants were asked to provide copies of the reports they deemed of importance in their respective roles. Although the interview protocols were adapted to job functions and the time allocated for the interview, some of the reoccurring themes are as follows (a) a general outline of the participant's role and how they use performance reporting information; (b) what kind of data they produce and analyze; (c) what are the performance criteria that are used, how are they translated into the reports, and why are they visualized the way they are; (d) the roles of reporting visualizations in tracking project performance; (e) how are the visualizations interpreted; (f) how frequently they use the artifacts in question; (g) on which specific features of the visualization they tend to focus on and why.

Most of the follow-ups revolved around the participants' interpretation of reports. These conversations focused on breaking down how the use of semiotic modes affects the interpretation of an artifact. For instance, we asked the participants to describe how a project performs just by looking at the information in a dashboard versus more text-based formats, and we then compared the answers to appreciate their distinctive communicative potential. 
Insights obtained from the interviews were substantiated by participant observation. The first author spent 30 days in the organization to observe the work of controls engineers in Program Controls. Throughout the duration of the fieldwork, the first author was given an office space in the open-plan office of Program Controls and had access to the reporting platform. The location in the headquarters facilitated the building of rapport with participants, offered an advantageous viewpoint to observe their work, and generated opportunities to partake in meetings and conversations. The observation was useful to test and compare what was reported during the interviews.

Throughout the development of this manuscript, we read newspaper articles discussing updates and issues in the delivery of MegaRail, which allowed us to test indirectly how some of our participants' claims were standing the test of time and gave us some perspective into how the megaproject was unfolding after the termination of our direct involvement in the organization.

\section{Data analysis}

The first step in the data analysis was the transcription of the interviews. After the transcription, a commentary section was added to each interview file, which enabled the connection of the interview data with the artifacts being discussed. Statements such as "I first look at this feature" and "I never consider that" were frequent and the commentary enabled the identification of the referents of these ostensive definitions. This process was fundamental to identify codes that helped us to classify interactions and observations connected to a specific theme. We took independent turns at analyzing the data throughout the various iterations of this manuscript and discussed emerging concerns through regular meetings to elaborate our ongoing interpretations.

The data analysis proceeded through the following activities: Analysis of observational data; analysis of interview data and follow-ups; visual and document analysis; triangulation. These phases were iterative and mutually informative, which helped to make sense of the data and its connection with insights from the literature. Each round of analysis followed a threelevel coding process to develop a sharper theoretical focus over time. In the initial step, our coding focused on qualifying how the reporting simplification effort unfolded in MegaRail. We then merged codes into first-order categories such as "focus on visual simplicity," "minimization of the use of numbers/text," "dis-/advantages of visual presentation formats," etc. In the second step of the analysis, we unpacked how different multimodal mixes generated meanings. We broke down how the meaning potential of specific multimodal mixes eventuated 
in each snapshot - for example, we coded for how specific artifacts allowed for the "development of overviews on data," "prompted comparisons," or "trivialized performance information," etc. In the last step of the analysis, we identified three distinctive relationships among semiotic modes that are discussed in depth in the findings - that is, what we call "imbuement," "juxtaposition," and "eclipsing." This final aspect of the coding process allowed us to develop the logical order in which reliance on the visual mode increased in the organization. Table 2 summarizes the roles of the multiple data sources in the development of our empirical narrative.

[Insert Table 2 about here]

The analysis of the interviews and observational data was coupled with the analysis of visual material collected in the field. Interviews and observations allowed us to identify the key pieces of evidence from the case. We first identified the recurrent features that establish a "family resemblance" among the artifacts produced in the setting (Kostelnick \& Hassett, 2003). In semiotic terms, artifacts such as performance dashboards and KPI visualizations are based on non-referential conventions. Their layouts suggest broad categories of meaning without aiming to create a close resemblance between image and referent and require a degree of conventional currency to become meaningful (Kostelnick \& Hassett, 2003). This is because these symbolic representations tend to be hard to learn and persist in cultural and professional applications thanks to how they are embedded in the way people think about specific problems (Ferguson, 1999). Accordingly, we focused on capturing interactions with a KPI visualization particular to MegaRail, the "worm diagram," which is perceived as the symbol of an approach to performance reporting that places considerable value on visual simplicity.

Connecting insights from interviews, visual and document analysis, and observation, we identified a series of interconnected episodes of engagement with performance reports that we refer to as snapshots. As Martinez and Cooper (2019) argue, snapshots are not meant to offer complete or representative accounts of how performance measurement visualizations shape "everything and anything" in a workspace. We use snapshots to detail how several multimodal mixes realize distinct multimodal relations among numbers, visuals, and text that affect meaning-making and interactions in contextualized instances of engagement. Our snapshots follow a logical order that seeks to capture how a distinctive approach to performance reporting gained conventional currency and the consequences it had on how users interpreted performance reports.

\section{Findings}


Our case study details how a highly visual approach to performance measurement was promoted, iteratively adapted, and experimented with in MegaRail. We focus on how senior figures appealed to the promises of the visual to promote a reporting simplification effort and on how reporting designers materialized this vision into increasingly simplified multimodal mixes.

\section{Setting the scene: Simplifying performance reports through the visual mode}

MegaRail's approach to introducing a new form of performance reporting emerged in response to the interpretative demands put on users by lengthy reports based on numbers and tables. A board member provided us with some perspective into how, historically, the leadership was dissatisfied with lengthy reports that were seen as "massive stacks of papers full of tables and numbers that were effectively not user friendly [...] if not almost impossible to interpret" (Board Member 1). The old board reports had "countless tables in the back, with pages and pages of line items, with a hundred line items" (Controls Engineer 2). This caused concern among the board who requested a reconceptualization of how performance information was delivered, focusing on simpler formats that would improve understanding and communication. This reconceptualization was understood by Program Controls as a minimization effort: "It was a push to minimize the amount of stuff we generate and to manage this minimalism in the entire controls function" (Controls Manager 1).

Many participants highlighted how the use of dashboards was typical for the style of the MegaRail director, who was referred to as a data visualization enthusiast and "would use dashboards extensively in his previous projects" (Senior Manager 3). Against this background, the reporting designers gradually moved away from highly numerical and textual templates and started to rely more on visual and graphical features. According to a board member:

There was a very deliberate drive. Culturally, the business, over the years, has been focused on providing information in a way that does make it usable. [...] The templates have evolved. We went through a process of understanding what is needed [...] and then starting to think: 'How do you present that?' [...] We found that graphical output gives you a stronger impact on differences between different projects, which facilitates understanding of what's happening (Board Member 1).

The quote highlights how graphical simplification was assumed to improve the reports' usability and understandability. This approach is encapsulated in Figure 1, which illustrates that the interrelationship between what the participants referred to as "artistry" and "business value" guides the production of reports. 
[Insert Figure 1 about here]

"Artistry" is here understood as an approach to information visualization that relies evocatively on the visual mode to generate involvement, while "business value" relates to the conventional presentation of performance information in tabular formats. Figure 1, which is taken from an internal presentation aimed to explain the new approach to performance reporting, illustrates the desire to make these two attributes converge towards a workable middle ground. It highlights the relationship between tabular formats that rely primarily on the numerical and textual modes (represented at the bottom of Figure 1) and data displays that depend mainly on the visual mode to orchestrate performance information. It also indicates MegaRail's belief in the visual mode's ostensive capacity to make reports usable and appealing (further along the "business value" axis). Not only does Figure 1 show that performance reporting is an inherently multimodal endeavor since it requires the use of numbers, text, and visuals, but it draws attention to the need to counterbalance the interpretative demands that different modes put on the user. As a reporting designer argues:

We always try to balance the 'cold, hard facts' [the numbers] with visuals and commentary to support understanding. [...] One needs to be very clear about how to present data and make sure people have an adequate understanding of what it all means. $[\ldots]$ It is not only about embellishing the documents (Controls Engineer 1).

The quote highlights that different modes can reinforce the message that a multimodal artifact conveys (e.g., the numerical mode conveys "hard" performance data, while visuals and commentary contextualize them to "support understanding"). However, when devising multimodal mixes some tensions can emerge:

There is no point in having a $99 \%$ accurate set of information that looks terrible because no one is ever going to look at it. Part of the art of program controls is making information visually capturing to the eye, so that people are drawn to it and want to ask questions (Senior Manager 2).

The quote shows that numerical accuracy can be at odds with features that seek to capture the eye. In the context of the simplification effort, ensuring that performance information "looks good" sought to prompt user engagement. Hence, implementing the reporting simplification took the form of a series of multimodal experimentations to improve communication and understanding.

The emphasis on the visual mode became a central pillar of this effort and was also motivated by an underlying skepticism towards numerical literacy: 
People aren't very good with numbers - and I include myself. [...] Even though I've got an accounting qualification [...] there are biases to what I remember when I'm reading these reports. [...] [To the contrary] if I look at this [dashboard] the first thing I pick up are the colors and the figures, because obviously the text is there and the ratios are there, but when you glance at something, it's the graphical input you get at first. $[\ldots]$ If you're looking at numbers, yes you have percentages, and yes you can say 'ok, this is a bit higher, this is a bit lower,' but many things can go wrong when people have to figure out numbers. [...] [Instead] red is red and that that's it. It's simpler (Senior Manager 3).

The quote illustrates the belief in some of the advantages of deploying multiple modes in performance reporting; it also shows that the reliance on the visual mode is seen as largely unproblematic by some senior figures. Notably, the immediacy of the visual mode also links to assumptions of how visual information processing can be quicker and more efficient than numerical alternatives:

People at board level prefer something visual because they can just look at it and directly see it. That's why we try to make graphical interpretation a lot quicker to look at. Having a visual representation allows you to process information sometimes faster, to see trends. Your mind can map things in a different manner versus reading (Controls Engineer 2).

The evidence stresses that visuals are expected to facilitate the engagement with performance reports. Additionally, the quotes convey expectations about the different meaning potential of semiotic modes: Visuals are assumed to convey meaning more directly than numbers in ways that may facilitate the processing of overarching trends. In what follows, we present four interconnected snapshots that explain how the reporting simplification effort became a material practice and detail the effects of several multimodal experimentations.

\section{Snapshot 1 - The visual imbuement of performance measurement information}

Figure 2 is a dashboard containing a summary of indicators regarding the program's main operational concerns. It is representative of the multimodal mixes that predated the reporting simplification effort. Figure 2 displays summary level information and focuses on design, safety, information management, quality, testing and commissioning, and sustainability. Multimodal features that stand out from the numerical data table are Red-Amber-Green color coding, performance trends indicated by colored arrows, and red boxes that highlight focus areas. The dashboard requires time, acquaintance, and technical knowledge to be comprehended.

[Insert Figure 2 about here] 
The dashboard's layout exemplifies the presentational style that the senior leadership took issue with when requesting a reporting redesign. These dashboards were deemed insufficiently user friendly and overly reliant on the numerical mode; for this reason, they became one of the first targets of the simplification effort. Notably, while the end goal was clear (i.e., reducing the length and detail of the reports), the designers were given considerable freedom regarding how to develop the new reports. The multimodal mix that emerged from this process became the most ubiquitous in MegaRail: The worm diagram (Figure 3).

\section{[Insert Figure 3 about here]}

The diagram is a summary-level presentation of the KPIs of a single project (e.g., the construction of a station) that offers a distinct overview of project performance and allows reducing the information presented in various reports. Adopting the diagram, the monthly reports on a project "were turned into a dashboard that catches the eye. This can fit in an A3 format. Previously this was a report that was probably 50 pages long" (Controls Engineer 1). The worm diagram is included in most reports (e.g., project dashboards, sector director reports, board reports, and program dashboards).

The worm diagram is multimodal because it deploys numbers, text, colors, and graphs. However, it strongly relies on the visual mode to convey a distinctive performance pattern, which stands at its center. The KPIs to the left side relate to the megaproject's four central concerns (i.e., safety, earned value, technical indicators, and performance assurance) and use color-coding to increase the visibility of their performance status. The worm diagram is a multimodal mix characterized by visual imbuement: The visual mode is foregrounded to infuse numerical and textual information with qualitative and visual difference. This visual imbuement is apparent in the line that joins the KPIs: The line has no meaning other than generating a pattern because the indicators are not reducible to a common metric and are constructed according to different formulae ${ }^{1}$.

Given the ubiquity of the diagram in MegaRail, we sought to retrospectively understand how it came about and why it gained conventional currency. One of the people involved in the development of the diagram recalls:

\footnotetext{
${ }^{1}$ For instance, the HSPI score (Health \& Safety Performance Index) is made up of two measures: The periodic Leading Indicator Performance score (measuring effort in terms of inputs/activities) and the latest Gateway score (measuring effectiveness as an output of their activities). Contrariwise, the TCPI score (To Complete Performance Index) expresses an estimation of the future cost performance needed to close out the project within the approved budget. The RAG boundary lines in figure 3 indicate the specific performance range for each KPI and they are not straight vertical lines because of the different and incommensurable formulae behind every indicator.
} 
We had a blank canvas. [...] There were 15, 20 different versions we went through in a couple of months. [...] At the beginning it was too text heavy. [...] We then tried to shuffle things around playing with graphs. I think we tried them all, we had stacked bar graphs, we had some pie charts, then we moved from the pie charts because they looked static. [...] We had a bar chart with the percentages written down as well underneath in a table. So, we had the same information presented graphically and quantitatively. That was not good. [...] We got [to the worm diagram] by avoiding information that was being doubly reported and reducing the quantitative stuff to the minimum (Controls Engineer 2).

The quote highlights how the diagram emerged through trial and error from the mandate to simplify performance reporting by using more visuals and minimizing the numerical mode. The inspiration for the worm diagram came from an unexpected source:

The inspiration was a graphic equalizer on an old-fashioned stereo, the display of the frequencies, but just turned on its side. [...] And what was useful about it was the simplicity. [...] Once you've explained 'to the right is good, to the left is bad,' everyone gets it (Senior Manager 2).

The diagram was developed to communicate how a project is performing in a distinguishable manner. This multimodal mix was developed to influence interpretations in a variety of ways. First, it aimed to attract the users' attention: Multimodal mixes that foreground unexpected patterns in combination with numbers were seen as more likely than other configurations that do not rely on the visual mode to attract attention and motivate engagement. Second, the diagram sought to influence interpretation by establishing a link between the simplicity of a multimodal mix and its capacity to engage the users: Artifacts that rely on simpler multimodal mixes were seen as more likely to be appropriated by actors in the organization.

The diagram was well-received by the Finance Director, who requested its systematic inclusion in most reports. Ensuring that the visual imbuement of performance reports acquired conventional currency was a concern from the onset:

A critical theme was standardization. We had to make sure every single report was literally identical. So, you know how to navigate the page, you know that on the righthand side is the worm with the data, and it's the same data you see on the dashboard, and then this section on the left is identical to the board report. It helps you navigate it quicker with that mix of diagrams and things. So that you focus the readers on what's important, and this mix of visuals and things hooks them much more (Senior Manager 1).

Such "standardization" can be expressed in multimodality terms through the notion of cohesion. Cohesion refers to a way of deploying semiotic modes that makes multimodal communication coherent by establishing a family resemblance among the multimodal mixes produced in a setting. The concern with deploying the worm diagrams cohesively shows an 
implicit understanding of how the visual mode is subject to less social regulation than text or numbers and, for this reason, it was seen to require coordinated efforts to ensure it was not interpreted in a purely idiosyncratic manner.

Snapshot 1 identified in the worm diagram the symbol of the effort to simplify performance reporting in MegaRail. We detailed how the diagram came about and how it imbued numbers and text with visual and qualitative difference. The diagram, with its capacity to make KPIs stand out in a dynamic manner, motivated the senior leadership to commit to the visual simplification of reporting even further, and they encouraged additional multimodal experimentations that would increase the reliance on the visual mode in Program Controls. In the next snapshot, we explore how the practice of the worm diagrams was consolidated further through a multimodal mix that juxtaposes various semiotic modes.

\section{Snapshot 2 - The juxtaposition among semiotic modes}

When Program Controls started rolling out the diagrams, they realized that the multimodal mixes acquired additional meaning potential if juxtaposed: The diagrams "are designed to be compared in a side-by-side way. If you look at them independently, you don't really pick up the differences" (Senior Manager 2). Program Controls developed the poster to facilitate comparisons and contrasts between diagrams (Figure 4). According to a senior manager:

After the worms, the poster was the next logical step to simplify everything and cut down some of the other stuff we produce [...] [The poster allows us] to put all the project information on one piece of paper that creates a dashboard that is the closest thing we have to a MegaRail program dashboard (Senior Manager 1).

[Insert Figure 4 about here]

The poster is a striking multimodal mix: The diagrams are placed prominently at the top of the poster and, below the diagrams, there is a wealth of financial performance information in graphical formats. The textual mode is present in green text boxes on the left side and in small, color-coded text boxes across the entire artifact:

The idea was to develop a sort of overview with the numbers, the worms, and lots of commentary boxes, either red or green boxes based on whether the news is good or bad. [...] We also wanted to show just how complex MegaRail is. [...] It's overwhelming at the beginning, but that's kind of the point. The idea was to nudge people to ask questions (Controls Engineer 1).

The poster rests on an oxymoronic tension: It simplifies the entire program's performance by collating information from fourteen project dashboards into a single artifact; simultaneously, it 
is a simplification that can overwhelm the user because of the richness of multimodal features it orchestrates. We examine its simplifying aspect first.

According to executive director 1 , the poster is "a reasonable simplification" because people need to spend time to interpret it:

I once worked out how much data is in here, and there's a lot of data, something like ten thousand data points, in a way that was just simply not digestible without the visualization. [...] This simplifies things a lot, and certain details are lost, but I'd challenge you to find the details if you had a 200 pages report instead (Senior Manager 4).

The evidence suggests that the performance information can be so granular that the details that are lost would be equally indiscernible in "tables that make everything look the same" (Controls Engineer 2). The poster makes project information detectable at a glance via the juxtaposition of the patterns: "You are reading the same information [as in the individual project reports], but here you very quickly can compare one project to another and get a sense of the bigger picture" (Senior Manager 1). Juxtaposition induces the reader to compare the shapes of multiple worm diagrams in a process that, over time, is seen to be intuitive: "Once you acclimatize people to it [...] just by glancing at the diagrams, your mind subconsciously processes them and sees the trends" (Senior Manager 2). Accordingly, the poster consistently emerged from the mandate of simplifying performance reporting.

Simultaneously and somewhat paradoxically, the poster's communicative potential is grounded in the richness of resources it makes available to the user. Numbers, graphs, colors, text, and patterns are deployed in a multimodal mix with an overwhelming size that engages the users in various ways. First, the dimensions of the artifact contribute to its dramatic character: "When you go to the room it's like 'Boom!' it's there. You immediately see the size, the scale, the amount of stuff in it!" (Controls Engineer 4). Second, once it has attracted attention, the multimodal mix sustains it by overwhelming the reader with information: The poster becomes "the focal point of the office $[\ldots]$ and acts as a conversation magnet. People come in, and they are immediately struck by how much information there is and want to understand it in context" (Senior Manager 2). Its multimodal complexity does not make attention converge on one feature that would provide an immediate answer and terminate the engagement with the artifact. This lack of a "bottom line" is seen to prompt inquiry, which is sustained by the richness of multimodal resources that call for attention. Here, it is not only the worms that are juxtaposed but the multiple semiotic modes in the poster that are in tension to capture the attention of the user. 
Snapshot 2 detailed how KPI representations characterized by visual imbuement were juxtaposed and enriched with other semiotic resources in a sizeable and eye-catching program dashboard. The reporting simplification effort materialized into this ambivalent multimodal mix that, leveraging the juxtaposition among patterns and semiotic modes, offered prompts for conversations and interactions. Paradoxically, the simplification effort generated an artifact that was seen as too onerous to interpret and distant from the idea of conveying information at a glance. For this reason, the reporting designers believed that the semiotic complexity of the poster was unsuitable for non-executive directors who were not especially familiar with the nuances of program delivery. In the following snapshot, we detail how the diagrams were simplified further for the board of directors.

\section{Snapshot 3 - The eclipsing of numbers and text}

In this snapshot, we explore a multimodal mix that most distinctively encapsulates the reporting simplification effort: The board report's summary page (Figure 5) - a further abstracted presentation of the diagrams at the top of the poster, displayed in A5 format. Figure 5 is arguably the culmination of the simplification of performance reporting:

This is what the approach to drastically change the reporting was all about. [...] 10,000 words down to 2,000 words, A4 down to A5, in PowerPoint 17 slides down to 5, 200 pages down to 20. And then all was in this one A5 piece of paper. [...] So, that was a quite deliberate policy; you've only got one page, you've got to make it fit, focus on what's important, consistently over time, and make it look good (Senior Manager 2).

The most surprising feature of Figure 5 is the extent to which it relies on the visual mode. The use of semiotic modes other than the visual is kept to a minimum (the textual mode is used only to name each project and KPI) or eclipsed (the numerical mode). As the term eclipsing suggests, while the diagrams are made quantitatively (they are constituted based on numerical formulas), the numerical mode is entirely concealed as the numbers are obscured by the diagrams' eye-catching configuration.

\section{[Insert Figure 5 about here]}

By the time the performance summary was rolled out, the diagrams had become the norm for most people dealing with reporting in the organization, and Figure 5 unveils the diagrams in their purest form:

Have you ever looked at viruses under a microscope? They wriggle. I look at them, and I treat each performance worm as the DNA of each project. You can look at this worm [pointing at the fourth worm in the first row], and it's very straight. But then, I look at this worm [pointing at the fourth worm in the second row] and it's all over the place, some of it is not even able to be shown. Each worm tells a different story, and the worm 
only comes into its own in this visual. [...] Only when you look at the worms side-byside, you get a general sense of just how different each project is performing (Senior Manager 1).

The quote shows that people had become so used to the diagrams that they were seen to be interpretable even though the numerical KPIs were eclipsed. While the board report included more detailed information, the visual appeal of Figure 5 and its minimalistic goal of breaking down the megaproject to its essentials influenced the interactions we witnessed. The people we observed discussing the diagrams implicitly developed two preferred readings. In Figure 5, we observed users "benchmarking" horizontally a KPI score in one project with other scores of the same indicator in other projects (e.g., to assess how the HSPI of contract 1 compares HSPI of contract 2, 3, etc.). In the absence of numerical KPIs, the benchmarking of indicators says little more than the binary interpretation that alignment "to the right is good, to the left is bad." The patterns can also be compared vertically thanks to how they interrelate incommensurable indicators. Vertically, odd patterns "immediately jump out because they look off" (Controls Engineer 2), and some of the KPI dots cannot be shown entirely because their scores deviate so much from the standard value that they are off the chart. This is another example of how the designers are not afraid to sacrifice detail to achieve appealing reports. However, the designers recognized that the purely visual comparison among patterns could induce oversimplified readings.

To address the issue, Program Controls pursued a particular communicative strategy: They developed a visual typology of the diagrams' shapes that manifests how the visual mode eclipsed other modes. When asked how one can make sense of Figure 5, Senior Manager 2 said the worms are "contract fingerprints" that allow the users to see if a project is "a basket case, chaotic, wriggly, consistent, or a gold star"- he illustrated this point showing the following image.

\section{[Insert Figure 6 about here]}

The visual typology of meaning is illustrative of the social regulation that informs the use of visuals in MegaRail. Importantly, while we occasionally heard people referring to the worms according to this nomenclature in our interviews, our observations suggest that - when interpreting the reports and commenting on the diagrams - the users were adopting the more simplistic and polarized language of good/bad performance, mainly focusing on the extreme ends of the visual typology. 
Importantly, the board report ${ }^{2}$ contains a wealth of information beyond the minimalism of Figure 5. The board report was reconceptualized to facilitate understanding of the program's performance for non-executive directors as the project deals with

Many areas of civil engineering, electrical engineering, operations, integration, testing, commissioning. Not all our board members are experts in all those fields, so it's making sure that the information that we present is intelligible for them (Senior Manager 3).

After the streamlining effort, the report contained approximately twenty A5 pages. Figure 5 precedes twelve A5 pages, each of which zooms in on each worm diagram. The objective of Figure 5 is to frame the interpretation of the report and focus discussions on the projects that require immediate attention. Further numerical and textual details are provided in the report, but the summary is presented as the default overview of the status of the program:

Ultimately, if someone wants the data behind [each worm diagram], they can go and find it from the reporting platform. [...] But you have to keep in mind that we're producing this report because there's discussion being held on it. It doesn't matter if it's 300,301 , or 302. [...] It matters how far the progress is and what's the change (Controls Engineer 1).

Hence, while the readers can dwell deeper on performance data, Figure 5 frames their perception towards the development of a highly simplified view of the program. The evidence shows that visual simplicity aimed to make information accessible to a heterogeneous audience as the visual mode was expected to allow the intuitive development of comparisons. Yet, Figure 5 emerged as too open to interpretation and - rather than pursuing more intuitive strategies such as increasing the level of detail or reintroducing some numerical information - Program Controls developed of a visual typology of meaning hoping to enable users to gain some insight from the performance summary.

This snapshot detailed the culmination of the effort to simplify performance reporting in MegaRail, which resulted in a performance summary where the visual mode eclipsed text and, crucially, numbers and framed the board's perception of the program's performance. In the last snapshot, we focus on the communicative consequences of the eclipsing of the numerical and textual modes.

\footnotetext{
${ }^{2}$ During the fieldwork, the board included ten people: Five board members had an engineering background and construction industry experience, two of them had a finance/auditing background, the remaining three did not have a technical background and were presumably less accustomed to the nuances of the operations in megaproject delivery. Up to ten more people were normally involved in board meetings, including executive directors and representatives from other functions such as HR, Legal, Communications, and Commercial. Some of them might be required to report ad hoc on specific issues, while others participated in every board meeting (e.g., the Chief of Staff). Board meetings took place every four weeks, and they took up to half a working day. The board report was the main document discussed in these meetings and was circulated to the attendees several days in advance.
} 


\section{Snapshot 4 - The worm diagram becomes a snake in disguise}

In this last snapshot, we explore the risks associated with the reporting simplification effort and the eclipsing of the numerical and textual modes in some of the key reporting documents used in MegaRail. We investigate how several senior leadership members reacted to Figure 5 and detail the frictions between the goals of Program Controls and the information needs of executive directors and board members.

Figure 5 aimed to frame the board's perception of project performance. However, it became an object of controversy. While the worm diagram in the original format containing the numerical KPIs (e.g., Figure 3) was widely accepted, the simplified presentation in Figure 5 became questioned because of its minimalism. The visual simplification and the eclipsing of the numerical and textual modes became seen as risky:

The classic phrase 'pictures tell a thousand words' is true only if you know what the picture is. The pictures here are very impressive, but we have to use them to explain what the situation is. [...] Because dashboards can hide things. [...] When something is described, there's always some optimism bias to say: 'These are our problems, as identified here.' And a dashboard is obviously a high-level representation of issues [...] but you never really know exactly what's lost once you have the dashboard there (Senior Manager 3).

The quote reinforces how the simplification required by the visualizing process implies that patterns of visibility and invisibility emerge from the reports. However, as argued by the executive director who earlier on called the poster a "reasonable simplification" of the program, simplification is also a matter of extent. The simplification of performance reporting and the reliance on visuals interact in powerful ways: The users can become so accustomed to the eclipsing of numbers and text that they may lose a sense of the meaning of the information at hand and its alleged referent.

Another participant highlighted some of the risks associated with these multimodal experimentations:

There is a risk that polishing things too much encourages the suppression of hard information. You must be careful not to be diversionary with the information you provide and never underestimate the behaviors it inculcates. [...] There's a risk that something like this, in a way that is recognizable and quick to absorb, just makes people feel good about the business and about themselves (Project Representative 1).

Hence, multimodal experimentations inspired by visual simplicity are open to the risk that the resulting artifacts may streamline their content so much that they actively conceal essential information. The quote also highlights how multimodal experimentations may get out of hand 
and inculcate a complacent attitude towards the interpretation of performance reporting. This critique is made even more explicit by Board Member 1 commenting on Figure 5:

That's probably where you say: 'I'm not so sure I would have given [the numbers] up'. Ultimately, it's getting close to a comfort picture and, at the end of the day, you could have lots of worms that look very straight. They may look so aligned because they all look consistent, but they could all be at the wrong end of the scale.

Hence, as the simplified diagrams become embedded in the organization, they can develop into comfort pictures that do not challenge existing understandings of project performance and may induce a complacent attitude towards performance reports. Therefore, the diagrams in which the numbers are eclipsed may trivialize the complexity of the megaproject to a simplistic polarity of good or bad performance and deter further scrutiny.

Additionally, the diagrammatic approach encapsulated in Figure 5 makes sense only if users are acclimatized with it, which may hinder a hypothetical change in performance criteria. When asked what would happen if a KPI was added, replaced, shifted in position, or removed from the worm, the participants did not offer compelling explanations as to how the diagrams can allow for a change in their layout. For instance, adding a KPI at the top, center, or bottom of the diagram would dramatically change the patterns and the users - as acclimatized as they are to their preferred readings, "contract fingerprints," and the eclipsing of numbers and text may not pick up the differences at a glance. These considerations make the simplified diagrams open to the risk of interpretative failures and highlight a paradoxical quality of the pursuit of visual simplicity. The diagrams were developed to imbue numbers with dynamic visual attributes that would make performance patterns stand out. However, as the users became accustomed to this approach, the "wriggling" of the patterns became lifeless and was seen to prompt the trivialization of performance information. In this sense, the worms can become "snakes in disguise," inducing complacency and a detrimental sense of reassurance. The effect of the eclipsing of the numerical and textual modes is specified below:

I've never seen reporting done better. But it looks so good that it discourages you to let the project managers just present a report. You also want to know what their judgment is. [...] This [pointing at Figure 5] gives you information at a glance, but there's no judgment in this. It's all factual. [...] At the end of the day, these are just KPIs. [...] There's a risk the reports look so good that they prevent judgment, and that can sometimes paralyze things (Executive Director 1).

Hence, pursuing simplicity in performance measurement may generate artifacts that are more akin to artworks produced for their own sake rather than pragmatic tools to track, control, and interrogate performance. Once users are accustomed to these visuals, the diagrams' patterns 
can acquire properties that resemble arbitrary binary codes (e.g., good or bad performance) rather than prompting engagement.

These considerations lend themselves to a comparison with the communicative potential of the poster in snapshot 2. In the poster, the richness of semiotic resources was shown to prompt curiosity in the users, motivating them to engage with a "conversation magnet" that supplied topics of conversations through the juxtaposition of semiotic modes. The semiotic complexity of the poster made it a simultaneously tantalizing and engaging multimodal mix. On the contrary, the analysis of Figure 5 highlights how the eclipsing of numbers and text and the foregrounding of the visual mode can create multimodal mixes that - albeit being alluring and even beautiful - may not offer enough opportunities for conversations and discussions and induce the trivialization of their information content, becoming "comfort pictures."

Hence, the visual mode can become so entrenched in the organization as to convey a misleading sense of matter-of-factness. In our case, as the visuals became "snakes in disguise," they provided a potentially detrimental sense of reassurance and self-referential character that impeded meaningful interactions with performance measures. In the discussion, we reflect on the theoretical implications of these findings for accounting scholarship interested in visual artifacts and multimodality.

\section{Discussion}

Performance reporting at MegaRail is an exemplary case of how visual approaches to performance measurement are experimented with and adopted and how managers appeal to the promises of the visual to materialize reporting simplification efforts. Extant literature has argued that as the use of visuals becomes more accepted and widespread in organizations and society, accounting visualizations become even more powerful communicative tools (Preston et al., 1996; Preston \& Young, 2000; Davison, 2010, 2014). Our findings challenge this position and demonstrate that, as the reliance on the visual increases and becomes embedded and subject to tight social regulation in performance measurement, the less powerful and engaging the performance measurement visualizations became as a result. The case study allows us to problematize several issues that are underdeveloped in research on the visual in performance measurement, which has thus far primarily highlighted the enabling consequences of visual artifacts and the simplification of accounting information (e.g., Quattrone, 2009; Free \& Qu, 2011; Pollock \& D’Adderio, 2012; Cooper et al., 2017; Jordan et al., 2018), while remaining largely silent on the drawbacks associated with an increase in reliance on visualizations. 
To make sense of our findings, we developed insights from research on multimodality. While issues of representation have been a longstanding interest in accounting scholarship (e.g., Hines, 1988; Tinker, 1991; Thompson, 1991; Chua, 1995; Mouritsen, 2011), multimodality offers novel theoretical resources to investigate how the communicative power of accounting representations depends on the distinct meaning-making potential of the varied semiotic modes they orchestrate, which remains insufficiently theorized in research on performance measurement. By tracing a sequence of multimodal experimentations, we showed how an organization transforms its performance measurement practices to increasingly rely on visuals relative to numbers and text. Unlike most visual research that focuses on the implementation of established performance measurement technologies (e.g., BSCs, Strategy Maps, or Magic Quadrants - see Busco \& Quattrone, 2015; Qu \& Cooper, 2011; Pollock \& D'Adderio, 2012), our focus on multimodal experimentations details how visual approaches to performance measurement that are developed ad hoc by an organization gain conventional currency.

In our findings, we identified three distinct multimodal relationships - imbuement, juxtaposition, and eclipsing. These multimodal relationships are individually insightful because they qualify how visuals, numbers, and text can interact in performance measurement artifacts, and they are sequentially meaningful because they explain how the lure of the visual manifested itself in the organization. By the lure of the visual, we refer to how an increase in the reliance on the visual mode (relative to numbers and text) can stifle the visualizations' communicative potential and reduce the opportunities for user engagement they offer.

In the first instance, the visual imbuement of KPIs allowed reducing the length and detail of performance reports, facilitating their appropriation by actors in the organization (snapshot 1). Imbuement refers to how the visual mode is used to make information stand out - via the development of a pattern that served no other purpose than connecting incommensurable KPIs -, thereby infusing numbers and text with visual and qualitative difference (e.g., Figure 3). Imbuement was key to increase the capacity of performance measurement to convey complex relations at a glance. Furthermore, we qualified how semiotic modes acquired additional meaning through juxtaposition (snapshot 2). Juxtaposition refers to how multimodal mixes that combine different accounts of performance (e.g., via visuals, numbers, and text) can capture users' attention and sustain engagement in virtue of the richness of their dissonant semiotic resources (e.g., Figure 4). We have shown how juxtaposition came to be perceived as at odds with the idea of simplifying reporting, and - for this reason - the reports were made to rely even more on the visual mode. Lastly, we qualified a multimodal 
relationship where the visual mode eventually started eclipsing numbers and text (snapshot 3). Although the users had access to more granular performance information in various formats, we demonstrated how highly simplified visual patterns of performance became an influential - albeit problematic - meaning-making resource. Eclipsing manifested in the way that the organization developed a cohesive visual typology of meaning to connect visual shapes to particular understandings of performance (Figure 6). In this sense, we are not suggesting that more detailed multimodal information was unavailable in the organization, but we unpacked how artifacts in which numbers and text are eclipsed became a central way through which many interactions were framed in the organization.

Most existing studies highlight how performance measurement visualizations become powerful because of the fabrication, improvisation, and patchwork interventions that go into their ongoing production (Preston et al., 1992; Chua, 1995; Dambrin \& Robson, 2011; Martinez $\&$ Cooper, 2019). Our case also highlights the importance of ongoing experimentations with performance visualizations. However, as part of these experimentations, the stripping of numerical and textual complexity eventually led to the performance measurement visualizations being practiced as if they had objective properties. Initially, the reliance on the visual mode aimed to turn "lifeless" tables that flatten their content into lively figures that would "wriggle," signal difference, and soften the performance measurement discourse. However, once the visual mode became so central as to eclipse text and numbers, performance measurement visualization acquired almost binary properties: A diagram aligned to the right was interpreted as performing "well" and one aligned to the left as doing "poorly." Despite the existence of other possible interpretations, this binary way of seeing became prevalent in the organization, influencing how users attributed meaning to the performance visualizations. Accordingly, as the reliance on the visual mode increased, our case suggests that highly visual multimodal mixes became "comfort pictures" - or minimalistic figures that lost their capacity to relate meaningfully to the quantitative information they contained, which remained backgrounded.

By focusing on the multimodal underpinnings of performance measurement artifacts, we showed how their simplification and even "beauty" can deter communication and interaction. This finding counters previous arguments that indicate how the visual simplification of accounting (Graham, 2008; Quattrone, 2009; Chakhovich \& McGoun, 2016) and performance measures (Espeland \& Stevens, 2008; Free \& Qu, 2011; Pollock \& D'Adderio, 2012) allows calculative technologies to become powerful in organizations. In our case, as the reliance on the visual mode increased, the more detached the reports became from 
the numerical constituents of performance measurement. While our findings do not suggest that simple visualizations are inherently dysfunctional, as an executive director argued there is a risk that the reports "look so good" that they deter engagement. Once the diagrams became deeply embedded and subject to tight social regulation in the reporting practices of the organizations (i.e., when they had sufficient conventional currency to be interpretable in the almost total absence of numerical KPIs and text), our analysis suggests that their simplicity disenfranchised the users from interrogating them.

Accordingly, the prevalent reliance on the visual mode extinguished some of the promises of visual approaches to performance measurement (e.g., the capacity to support understanding, make information actionable, and prevent biased evaluations), as minimalistic reports became lifeless and eventually limited opportunities available to users. This deepens our critique of studies that, adopting functionalist approaches (e.g., Kinsella, 2019; Isset \& Hicks, 2017; Tufte, 2001) and experimental methodologies (e.g., Lipe \& Salterio, 2000; VeraMuñoz et al., 2001; Cardinaels, 2008), maintain that visualizations are influential in virtue of their inherent characteristics and underplay the importance of norms and conventions that inform their practice. In our case, once people became accustomed to the visual approach to performance measurement, the perceived simplicity of the reports became constraining as overpolished visuals induced the trivialization of performance information.

A plethora of studies in accounting (e.g., Tinker, 1991; Thompson, 1991), the sociology of quantification (e.g., Porter, 1995; Mennicken \& Espeland, 2019), and organization theory (e.g., Mazmanian \& Beckman, 2018; Arjaliès \& Bansal, 2018) has shown that numbers and quantitative measures can perpetuate mechanical objectivity, oversimplify, and can become endowed with a factual appeal that makes them instinctively and deceivingly trustworthy. We find that simple performance visualizations can be practiced in a manner that is similarly detached and decontextualized. Our multimodal analysis suggests that a richness of semiotic resources where multiple modes are juxtaposed can be more conducive to prompt curiosity and interpretation among the users of performance reports. For example, the poster (figure 4) was shown to allow the generation of a variety of multimodal messages that worked as a "conversation magnet" by supplying to managers topics of conversation and opportunities for engagement. Hence, the juxtaposition of multiple modes and the semiotic richness of performance measurement artifacts can be more conducive to engagement than simpler, clean, and polished alternatives.

The last defining characteristic of our case relates to how the change in the use of the visual mode unfolded in the organization. Extant research in accounting (e.g., Bloomfield \& 
Vurdubakis, 1997; Qu \& Cooper, 2011; Busco \& Quattrone, 2015) and multimodality (e.g., Meyer et al., 2018; Barberá-Tomás et al., 2019; Höllerer et al., 2019) suggest that visual practices are largely emergent in nature and their changes tend to unfold in a bottom-up fashion. In our case, the change towards the use of visuals in performance reporting was top-down. Not only did some senior figures in the organization initiate the reconceptualization of the reporting but also substantial effort went into its enforcement. A concern of the senior leadership was subjecting the use of visuals to tight social regulation from the beginning of the change effort to mitigate the polysemy (Macintosh, 2002; Davison, 2014) and interpretative ambiguity (Qu \& Cooper, 2011; Pollock \& D’Adderio, 2012) that characterizes visualizations. Multimodality literature contends that the visual mode is normally mobilized to convey meanings that are not yet legitimate because of its capacity to fly under the radar and its low social regulation (Jancsary et al., 2018; Barberá-Tomás et al., 2019; Knight \& Tsoukas, 2019). Existing multimodality frameworks would suggest that the visual mode tends to be used covertly to infiltrate existing practices and favor the placement of new ideas: "By refraining from explicit argument and specification, visuals [...] achieve initial placement without challenging entrenched understandings or wrestling with known lines of contestation" (Meyer et al., 2018, p.402). In our case, the promises of the visual directly challenged the entrenched practice of producing reports that had previously relied primarily on text and numbers. This distinctive feature of our case is indicative of the pervasiveness that discourses surrounding the promises of the visual are acquiring in organizations and the legitimacy that is associated with the visual mode, which reiterates the timely importance of developing a theoretical understanding of their risks, unintended consequences, and limitations.

\section{Contributions and concluding remarks}

Our first contribution consists in the substantive qualification of some of the risks and consequences of performance measurement visualizations, which are undertheorized in existing accounting scholarship (e.g., Quattrone, 2009; Dambrin \& Robson, 2011; Qu \& Cooper, 2011; Pollock \& D’Adderio, 2012; Jordan et al., 2018; Martinez \& Cooper, 2019). In our case, as performance measurement visualizations gained sufficient conventional currency to be interpretable even if numbers and text were eclipsed, they gradually came to deter engagement, induced the trivialization of performance information, and limited the interactive opportunities available to users. The social regulation of visuals resulted in a progressive stripping of their semiotic complexity, which undermined the exercise of judgment and frustrated most of the promises of visual approaches to performance measurement. We call this 
phenomenon the lure of the visual: a seemingly paradoxical process, whereby increasing reliance on the visual mode results in a stifling of the visualizations' communicative potential, reducing the opportunities for engagement and meaning making they offer to users. Our findings challenge the extant literature that, proclaiming the existence of a "visual turn" in contemporary society and organizations, interprets the ubiquity and legitimacy of accounting visualizations as factors that further increase their relevance and communicative power (Preston et al., 1996; Graves et al., 1996; Preston \& Young, 2000; Davison, 2014, 2015). Through our empirical analysis, we found something different: Relying primarily on the visual mode in performance measurement can paradoxically exhaust much of the power commonly attributed to visualizations in organizations. Accordingly, our theorization of the lure of the visual addresses a blind spot in the extant research that has focused primarily on the enabling consequences of performance measurement visualizations (e.g., Espeland \& Stevens, 2008; Quattrone, 2009; Qu \& Cooper, 2011; Pollock \& D’Adderio, 2012; Jordan et al., 2018; Martinez \& Cooper, 2019). The constitutive link between the effects of these visualizations and the importance of the conventions that shape their use also challenges the prescriptions of functionalist advocates of data visualizations (e.g., Kinsella, 2019; Berinato, 2016; Issett \& Hicks, 2017; Tufte, 2001) and experimental proponents of visual approaches to performance measurement (e.g., Vera-Muñoz et al., 2001; Lipe \& Salterio, 2002; Cardinaels, 2008; Cardinaels \& van Veen-Dirks, 2010). This literature, foregrounding only the cognitive factors that shape engagement with visualizations, contend that visual artifacts have inherently enabling properties and neglect the drawbacks of their consolidated practice.

Our second contribution to the accounting literature consists in the qualification of how multiple semiotic modes interact in performance measurement artifacts, affecting how they can generate meaning in organizations. Focusing on how the meaning of accounting representations depends on multiple semiotic modes overcomes some of the limitations of monomodal accounts of meaning-making (e.g., Boland, 1993; Macintosh, 2002; Lorino et al., 2017; Hayoun, 2019) or approaches that reify visual meaning by isolating it from the broader communicative context (e.g., Preston et al., 1996; Preston \& Young, 2000; Davison, 2010, 2014). Building on insights from multimodality research (e.g., Kress, \& van Leuween, 2006; Kress, 2009) and its recent development in organizational scholarship (e.g., Meyer et al., 2018; Barberá-Tomás et al., 2019; Knight \& Tsoukas, 2019; Lefsrud et al., 2020), our study introduces a multimodal approach to accounting and performance measurement. Through our snapshots, we have identified three multimodal relationships between the visual, numerical, and textual semiotic modes: Imbuement, juxtaposition, and eclipsing. By theorizing the 
connections among such relationships, we have detailed how the reliance and progressive foregrounding of the visual mode unfolded in the case organization and its communicative effects. We have shown that multimodal mixes that combine a wealth of different semiotic resources can spark curiosity and sustain interactions with performance reports, whereas simple, clean, and polished reports may deter engagement. This adds further nuance to studies that have problematized how the consolidation of visual approaches to accounting and performance measurement may prevent these artifacts from invoking tensions, generate conversations, and prompt inquiry (Mouritsen, 2011; Busco \& Quattrone, 2015; Quattrone, 2017; Arjaliès \& Bansal, 2018). Through our multimodal analysis, we shed new light on the operation of different types of accounting representations, and we qualified how the foregrounding and social regulation of the visual mode can have counterproductive consequences by failing to generate critical interactions.

Lastly, our study has implications for future research on multimodality in organizations and its relationship to accounting scholarship. A set of multimodality contributions has thus far primarily illuminated how the textual and the visual semiotic modes play out in organizations (Meyer et al., 2018; Barberá-Tomás et al., 2019; Höllerer et al., 2019; Knight \& Tsoukas, 2019; Lefsrud et al., 2020). However, the numerical semiotic mode's meaning potential and that of technologies of calculation more broadly was uncharted territory for multimodality scholars. This study sought to create a fertile ground for interdisciplinary accounting and organizational research on multimodality to become mutually informative.

Given our focus on performance measurement, we centered our theoretical discussions and empirical analysis on how three modes interact: Visuals, text, and numbers. However, there is room for further development on how other modes, such as the spatial mode, moving image and interactive visualizations, or audio resources play out in accounting and performance measurement. Expanding the multimodal scope of accounting research could shed new light on how different accounting innovations gain traction in virtue of their multimodal workings and how they are implicated in the creation, maintenance, and/or transformation of meanings. In addition, exploring how performance measurement technologies are subtly embedded in our daily lives, disguising themselves in visually appealing multimodal mixes (see Knight \& Tsoukas, 2019; Begkos \& Antonopoulou, 2020; Bandola-Gill et al., 2021), is important to understand how technologies of calculation are evolving through technological change and how they seek to appeal to new audiences. Finally, there is room for further investigation into how different multimodal mixes frame, prompt, or hinder, engagement with non-traditional 
reporting concerns that are becoming of increasing importance, such as climate risk or sustainability reporting. 


\section{References}

Aral, S. (2013). To go from big data to big insight, start with a visual. Harvard Business Review: < https://hbr.org/2013/08/visualizing-how-online-word-of >, [Accessed 29/06/2021].

Arjaliès, D. L., \& Bansal, P. (2018). Beyond numbers: How investment managers accommodate societal issues in financial decisions. Organization Studies, 39(5-6), $691-719$.

Andon, P., Baxter, J., \& Chua, W.F. (2015). Accounting for stakeholders and making accounting useful. Journal of Management Studies, 52(7), 986-1002.

Ashcraft, K. L., Kuhn, T. R., \& Cooren, F. (2009). Constitutional amendments: "Materializing" organizational communication. Academy of Management Annals, (3), 1-64.

Ashkenas, R. (2007). Simplicity-minded management. A practical guide to stripping complexity out of your organization. Harvard Business Review, 85(12), 101-109.

Bandola-Gill, J., Grek, S., \& Ronzani, M. (2021). Beyond winners and losers: Ranking visualizations as alignment devices in global public policy. Research in the Sociology of Organizations, 74, 27-52.

Barberá-Tomás, D., Castelló, I., de Bakker, F.G.A., \& Zietsma, C. (2019). Energizing through visuals: How social entrepreneurs use emotion-symbolic work for social change. Academy of Management Journal, 62, 1789-1817.

Beattie, V.A., \& Jones, M.J. (1992). The use and abuse of graphs in annual reports: Theoretical framework and empirical study. Accounting and Business Research, 22(88), 291-303.

Begkos, C., \& Antonopoulou, K. (2020). Measuring the unknown: Evaluative practices and performance indicators for digital platforms. Accounting, Auditing \& Accountability Journal, 33(3),588-619.

Berger, P.L., \& Luckmann, T. (1967). The social construction of reality: A treatise in the sociology of knowledge. New York: Anchor Books.

Berinato, S. (2016). Visualizations that really work. Harvard Business Review, 94(6), 93-100.

Bloomfield, B.P. \& Vurdubakis, T. (1997). Visions of organization and organizations of vision: The representational practices of information systems development. Accounting, Organizations and Society, 22(7), 639-666.

Boedker, C., \& Chua, W.F. (2013). Accounting as an affective technology: A study of circulation, agency and entrancement. Accounting, Organizations and Society, 38(4), 245-267.

Boedker, C., Chong, K.M., \& Mouritsen, J. (2019). The counter-performativity of calculative practices: Mobilising rankings of intellectual capital. Critical Perspectives on Accounting, article in press.

Boland, R.J. (1993). Accounting and the interpretive act. Accounting, Organizations and Society, 18, 125-146. 
Briers, M., \& Chua, W. F. (2001). The role of actor-networks and boundary objects in management accounting change: a field study of an implementation of activity-based costing. Accounting, Organizations and Society, 26(3), 237-269.

Busco, C., \& Quattrone, P. (2015). Exploring how the Balanced Scorecard engages and unfolds: Articulating the visual power of accounting inscriptions. Contemporary Accounting Research, 32(3), 1236-1262.

Cardinaels, E. (2008). The interplay between cost accounting knowledge and presentation formats in cost-based decision-making. Accounting, Organizations and Society, 33(6), $582-602$.

Cardinaels, E., \& van Veen-Dirks, P.M.G. (2010). Financial versus non-financial information: The impact of information organization and presentation in a Balanced Scorecard. Accounting, Organizations and Society, 35(6), 565-578.

Carlsson-Wall, M., Chua, W. F., \& Kraus, K. (2019). Accounting and passionate interests: The case of a Swedish football club. Accounting, Organizations and Society, 74, 21-40.

Chakhovich, T., \& McGoun, E.G. (2016). Why grids in accounting? Critical Perspectives on Accounting, 34(1), 36-59.

Chambers, R.J. (1999). The case for simplicity in accounting. Abacus, 35, 121-137.

Cheng, M.M., \& Humphreys, K.A. (2012). The differential improvement effects of the strategy map and scorecard perspectives on managers' strategic judgments. The Accounting Review, 87(3), 899-924.

Chua, W.F. (1995). Experts, networks and inscriptions in the fabrication of accounting images: A story of the representation of three public hospitals. Accounting, Organizations and Society, 20(2-2), 111-145.

Chua, W.F., \& Degeling, P. (1993). Interrogating an accounting-based intervention on three axes: Instrumental, moral and aesthetic. Accounting, Organizations and Society, 19(4), 291-318.

Cooper, D.J., \& Morgan, W. (2008). Case study research in accounting. Accounting Horizons, 22 (2), 159-178.

Cooper, D.J., \& Ezzamel, M. (2013). Globalization discourses and performance measurement systems in a multinational firm. Accounting, Organizations and Society, 38(4), 288313

Cooper, D.J., Ezzamel, M., \& Qu, S. (2017). Popularizing a Management Accounting Idea: The Case of the Balanced Scorecard. Contemporary Accounting Research, 34, 9911025.

Cornelissen, J.P., Durand, R., Fiss, P.C., Lammers, J.C., \& Vaara, E. (2015). Putting communication front and center in institutional theory and analysis. Academy of Management Review, 40, 10-27.

Dambrin, C., \& Robson, K. (2011). Tracing performance in the pharmaceutical industry: Ambivalence, opacity and the performativity of flawed measures. Accounting, Organizations and Society, 36(7), 428-445. 
Davison, J. (2010). [In]visible [in]tangibles: Visual portraits of the business élite. Accounting, Organizations and Society, 35, 165-183.

Davison, J. (2014). Visual rhetoric and the case of intellectual capital. Accounting, Organizations and Society, 39(1), 20-37.

Davison, J. (2015). Visualising accounting: an interdisciplinary review and synthesis. Accounting and Business Research, 45 (2), 121-165.

Desanctis, G., \& Jarvenpaa, S. L. (1989). Graphical presentation of accounting data for financial forecasting: An experimental investigation. Accounting, Organizations and Society, 14(5-6), 509-525.

Eppler, M.J. \&, Platts, K.W. (2009). Visual strategizing. The systematic use of visualizations in the strategic-planning process. Long Range Planning, 42, 42-74.

Espeland, W.N., \& Stevens, M.L. (2008). A sociology of quantification. European Journal of Sociology, 49(3), 401-436.

Ferguson, E.S. (1999). Engineering and the mind's eye. Cambridge: The MIT Press.

Flyvbjerg, B. (2014). What you should know about megaprojects and why: An overview. Project Management Journal, 7(3), 47-67.

Free, C., \& Qu, S.Q. (2011). The use of graphics in promoting management ideas: An analysis of the Balanced Scorecard, 1992-2010. Journal of Accounting and Organizational Change, 7(2), 158-189.

Gagliardi, P. (2006). Exploring the aesthetic side of organizational life. In: Clegg, S., Hardy, C., Lawrence, T., \& Nord, W. (Eds.). The SAGE Handbook of Organization Studies. London: SAGE, 701-724.

Gatzweiler, M.K., \& Ronzani, M. (2019). Prospective sensemaking and thinking infrastructures in a large-scale humanitarian crisis. Research in the Sociology of Organizations, 62, 85-112.

Graham, C. (2008). Fearful asymmetry: The consumption of accounting signs in the Algoma steel pension bailout. Accounting, Organizations and Society, 33 (7-8), 756-782.

Graves, O., Flesher, D., \& Jordan, R. (1996). Pictures and the bottom line: Television and the epistemology of US annual reports. Accounting, Organizations and Society, 21 (1), 5788.

Green, S. E. (2004). A rhetorical theory of diffusion. Academy of Management Review, 29, 653-669.

Halliday, M.A.K. (1978). Language as social semiotic. London: Arnold.

Hayoun, S. (2019). How fair value is both market-based and entity-specific: The irreducibility of value constellations to market prices. Accounting, Organizations and Society, 73, 68-82.

Hines, R.D. (1988). Financial accounting: In communicating reality, we construct reality. Accounting, Organizations and Society, 13(3), 251-261. 
Höllerer, M., van Leeuwen, T., Jancsary, D., Meyer, R. E., Andersen, T., \& Vaara, E. (2019). Visual and multimodal research in organization and management studies. London: Routledge.

Hoskin, K.W., \& Macve, R.H. (1986). Accounting and the examination: A genealogy of disciplinary power. Accounting, Organizations and Society, 11(2), 105-136.

Isset, K.R., \& Hicks, D.M. (2017). Providing public servants what they need: Revealing the "unseen" through data visualization. Public Administration Review, 78(3), 479-485.

Jack, L. (2013). Accounting communication inside organizations. In: Jack, L., Davison, J., \& Craig, R. (Eds.). The Routledge Companion to Accounting Communication. London: Routledge.

Jancsary, D., Meyer, R.E., Höllerer, M.A., \& Boxenbaum, E. (2018). Institutions as multimodal accomplishments: Towards the analysis of visual registers. Research in the Sociology of Organizations, 54, 87-117.

Jordan, S., Mitterhofer, H. \& Jørgensen, L. (2018). The interdiscursive appeal of risk matrices: collective symbols, flexibility normalism and the interplay of 'risk' and 'uncertainty'. Accounting, Organizations and Society, 67, 34-55.

Justesen, L., \& Mouritsen, J. (2009). The triple visual: translations between photographs, 3-D visualizations and calculations. Accounting, Auditing \& Accountability Journal, 22(6), 973-990.

Kahneman, D. (2011). Thinking, fast and slow. New York: Farrar, Straus and Giroux.

Kinsella, S. (2019). Visualising economic crises using accounting models. Accounting, Organizations and Society, 75, 1-16.

Knight, E., \& Tsoukas, H. (2019). When fiction trumps truth: What 'post-truth' and 'alternative facts' mean for management studies. Organization Studies, 40(2), 183-197.

Kostelnick, C., \& Hassett, M. (2003). Shaping information: The rhetoric of visual conventions. Carbondale: Southern Illinois University Press.

Kress, G. (2009). Multimodality: Exploring contemporary methods of communication. New York: Routledge.

Kress, G., \& van Leeuwen, T. (2006). Reading images: The grammar of visual design. London: Routledge.

Lefsrud, L.M., Graves, H., \& Phillips, N. (2020). "Giant toxic lakes you can see from space": A theory of multimodal messages and emotion in legitimacy work. Organization Studies, 41(8), 1055-1078.

Lipe, M. G., \& Salterio, S.E. (2000). The balanced scorecard: Judgmental effects of common and unique performance measures. The Accounting Review, 75(3), 283-298.

Lipe, M.G., \& Salterio, S.E. (2002). A note on the judgmental effects of the balanced scorecard's information organization. Accounting, Organizations and Society, 27(6), $531-540$. 
Lorino, P., Mourey, D., \& Schmidt, G. (2017). Goffman's theory of frames and situated meaning making in performance reviews. The case of a category management approach in the French retail sector. Accounting, Organizations \& Society, 58, 32-49.

Luckmann, T. (2006). Die kommunikative Konstruktion der Wirklichkeit. In Tänzler, D., Soeffner, H., \& Knoblauch, H. (Eds.), Neue Perspektiven der Wissenssoziologie. Konstanz: UKV Verlag, 15-26.

Macintosh, N. (2002). Accounting, accountants and accountability. London: Routledge.

Martinez, D.E., \& Cooper, D.J. (2019). Assembling performance measurement through engagement. Accounting, Organizations and Society, article in press.

Manochin, M., Brignall, S., Lowe, A., \& Howell, C. (2011). Visual modes of governmentality: Traffic lights in a housing association. Management Accounting Research, 22, 26-35.

Mazmanian, M. \& Beckman, C.M. (2018). "Making" your numbers: Engendering organizational control through a ritual of quantification. Organization Science, 29(3) $357-379$

Mennicken, A., \& Espeland, W.N. (2019). What's new with numbers? Sociological approaches to the study of quantification. Annual Review of Sociology, 45, 223-245.

Meyer, R.E., Jancsary, D., Höllerer, M.A., \& Boxenbaum, E. (2018). The role of verbal and visual text in the process of institutionalization. Academy of Management Review, 43(3), 489-555.

Mouritsen, J. (2011). The operation of representation in accounting: A small addition to Dr. Macintosh's theory of accounting truths. Critical Perspectives on Accounting, 22, 228235.

Pollock, N. \& D'Adderio, L. (2012). Give me a two-by-to matrix and I will create the market: rankings, graphic visualization and sociomateriality. Accounting, Organizations and Society, 37, 565-586.

Porter, T.M. (1995). Trust in numbers: The pursuit of objectivity in science and public life. Princeton: Princeton University Press.

Preston, A.M., Cooper, D.J., \& Coombs, R.W. (1992). Fabricating budgets: A study of the production of management budgeting in the national health service. Accounting, Organizations and Society, 17(16), 561-593.

Preston, A.M., Wright, C., \& Young, J.J. (1996). Imag[in]ing annual reports. Accounting, Organizations and Society, 21(1), 113-137.

Preston, A.M., \& Young, J.J. (2000). Constructing the global corporation and corporate constructions of the global: A picture essay. Accounting, Organizations and Society, 25(4), 427-449.

Puyou, F.R., \& Quattrone, P. (2018). The visual and material dimensions of legitimacy: Accounting and the search for socie-ties. Organization Studies, 39(5-6), 721-746.

Qu, S., \& Cooper, D.J. (2011). The role of inscriptions in producing a balanced scorecard. Accounting, Organizations and Society, 36 (6), 1-19. 
Quattrone, P. (2009). Books to be practiced: Memory, the power of the visual, and the success of accounting. Accounting, Organizations and Society, 34(1), 85-118.

Quattrone, P. (2016). Management accounting goes digital: Will the move make it wiser? Management Accounting Research, 31, 118-122.

Quattrone, P. (2017). Embracing ambiguity in management controls and decision-making processes: On how to design data visualizations to prompt wise judgement. Accounting and Business Research, 47(5), 588-612.

Suddaby, R., \& Greenwood, R. (2005). Rhetorical strategies of legitimacy. Administrative Science Quarterly, 50, 35-67.

Suzuki, T. (2003). The accounting figuration of business statistics as a foundation for the spread of economic ideas. Accounting, Organizations and Society, 28(1), 65-95.

Tableau (2020). Business intelligence and analytics software - Tableau. Available online at: < https://www.tableau.com/en-gb > [Accessed 01/02/20].

Themsen, T.N., \& Skærbæk, P. (2018). The performativity of risk management frameworks and technologies: The translation of uncertainties into pure and impure risks. Accounting, Organizations and Society, 67, 20-33.

Tinker, T. (1991). The accountant as partisan. Accounting, Organizations and Society, 16(3), 297-310.

Thompson, G. (1991). Is accounting rhetorical? Methodology, Luca Pacioli and printing. Accounting, Organizations and Society, 16, 572-599.

Thompson, G. (1998). Encountering economics and accounting: Some skirmishes and engagements. Accounting, Organizations and Society, 23(3), 283-323.

Tufte, E.R. (2001). The visual display of quantitative information. Cheshire: Graphics Press.

Vera-Muñoz, S.C., Kinney, W.R., \& Bonner, S.E. (2001). The effects of domain experience and task presentation format on accountants' information relevance assurance. The Accounting Review, 76(3) 405-429. 
Tables and figures

\begin{tabular}{|c|c|c|}
\hline Interviewee & $\begin{array}{c}\text { Number of } \\
\text { interviews \& } \\
\text { follow-ups }\end{array}$ & $\begin{array}{l}\text { Duration } \\
\text { (Approx.) }\end{array}$ \\
\hline Controls Engineer 1 & 4 & $1 \mathrm{~h} ; 30 \mathrm{~m} ; 30 \mathrm{~m} ; 30 \mathrm{~m}$ \\
\hline Controls Engineer 2 & 2 & $1 \mathrm{~h} ; 1 \mathrm{~h}$ \\
\hline Controls Engineer 3 & 1 & $45 \mathrm{~m}$ \\
\hline Controls Engineer 4 & 1 & $45 \mathrm{~m}$ \\
\hline Controls Engineer 5 & 1 & $1 \mathrm{~h}$ \\
\hline Controls Engineer 6 & 1 & $45 \mathrm{~m}$ \\
\hline Controls Engineer 7 & 1 & $45 \mathrm{~m}$ \\
\hline Controls Manager 1 & 2 & $1 \mathrm{~h} ; 1 \mathrm{~h}$ \\
\hline Controls Manager 2 & 1 & $1 \mathrm{~h}$ \\
\hline Senior Manager 1 & 2 & $1 \mathrm{~h} 30 \mathrm{~m} ; 2 \mathrm{~h}$ \\
\hline Senior Manager 2 & 3 & $2 \mathrm{~h} ; 1 \mathrm{~h} ; 45 \mathrm{~m}$ \\
\hline Senior Manager 3 & 1 & $1 \mathrm{~h}$ \\
\hline Senior Manager 4 & 1 & $1 \mathrm{~h}$ \\
\hline Senior Manager 5 & 2 & $45 \mathrm{~m} ; 45 \mathrm{~m}$ \\
\hline Senior Manager 6 & 1 & $1 \mathrm{~h}$ \\
\hline Executive Director 1 & 1 & $45 \mathrm{~m}$ \\
\hline Executive Director 2 & 2 & 1h 30m; 30m \\
\hline Executive Director 3 & 1 & $1 \mathrm{~h}$ \\
\hline Executive Director 4 & 1 & $1 \mathrm{~h} 30 \mathrm{~m}$ \\
\hline Board Member 1 & 1 & $1 \mathrm{~h}$ \\
\hline Board Member 2 & 1 & $45 \mathrm{~m}$ \\
\hline Project Representative 1 & 1 & $2 \mathrm{~h}$ \\
\hline Project Representative 2 & 1 & $30 \mathrm{~m}$ \\
\hline Project Manager 1 & 1 & $1 \mathrm{~h} 30 \mathrm{~m}$ \\
\hline Project Manager 2 & 1 & $1 \mathrm{~h}$ \\
\hline Project Manager 3 & 1 & $1 \mathrm{~h}$ \\
\hline Project Manager 4 & 1 & $1 \mathrm{~h}$ \\
\hline External Consultant 1 & 1 & $1 \mathrm{~h}$ \\
\hline External Consultant 2 & 1 & $1 \mathrm{~h}$ \\
\hline External Consultant 3 & 1 & $1 \mathrm{~h}$ \\
\hline
\end{tabular}

Table 1. Schedule of interviews (2017-2018). 


\begin{tabular}{|c|c|c|}
\hline Activities & Intended Outcomes & Achieved Outcomes \\
\hline $\begin{array}{c}\text { Analysis of data from } \\
\text { observation and pilot } \\
\text { study }\end{array}$ & $\begin{array}{l}\text { Exploration of themes } \\
\text { and relationships in situ } \\
\text { - Development of final } \\
\text { semi-structured } \\
\text { interview protocol }\end{array}$ & $\begin{array}{l}\text { - Observation of practices } \\
\text { of engagement with } \\
\text { visualizations } \\
\text { - Identification of themes } \\
\text { to be explored in } \\
\text { interviews } \\
\text { - Interview protocol }\end{array}$ \\
\hline $\begin{array}{l}\text { Analysis of interview data } \\
\text { and follow-ups }\end{array}$ & $\begin{array}{l}\text { - Exploration of the } \\
\text { participants' views on } \\
\text { the identified themes } \\
\text { - Emergence of new } \\
\text { themes } \\
\text { - Insight into the design } \\
\text { and practice of artifacts }\end{array}$ & $\begin{array}{l}\text { - } \begin{array}{l}\text { Relationships with } \\
\text { observational data }\end{array} \\
\text { - Accounts of design and } \\
\text { practice of artifacts } \\
\text { - Features deemed } \\
\text { influential in use } \\
\text { - Recurrent interpretations } \\
\text { of artifacts }\end{array}$ \\
\hline $\begin{array}{c}\text { Visual and document } \\
\text { analysis }\end{array}$ & $\begin{array}{l}\text { Insights from the } \\
\text { analysis of the semiotic } \\
\text { modes used in the } \\
\text { reports } \\
\text { - Identification of } \\
\text { reoccurring features }\end{array}$ & $\begin{array}{l}\text { Discrepancies with } \\
\text { interview data } \\
\text { - Insights into the formal } \\
\text { features of artifacts }\end{array}$ \\
\hline $\begin{array}{l}\text { Additional analysis of the } \\
\text { data }\end{array}$ & $\begin{array}{l}\text { Triangulation between } \\
\text { observation, interviews, } \\
\text { and multimodal analysis } \\
\text { Development of second- } \\
\text { order themes }\end{array}$ & $\begin{array}{l}\text { - Identification of multiple } \\
\text { snapshots as processual } \\
\text { episodes of engagement } \\
\text { - Identification of the } \\
\text { prevalence of specific } \\
\text { layouts } \\
\text { - Analysis as presented in } \\
\text { the findings }\end{array}$ \\
\hline
\end{tabular}

Table 2. Phases of data analysis. 


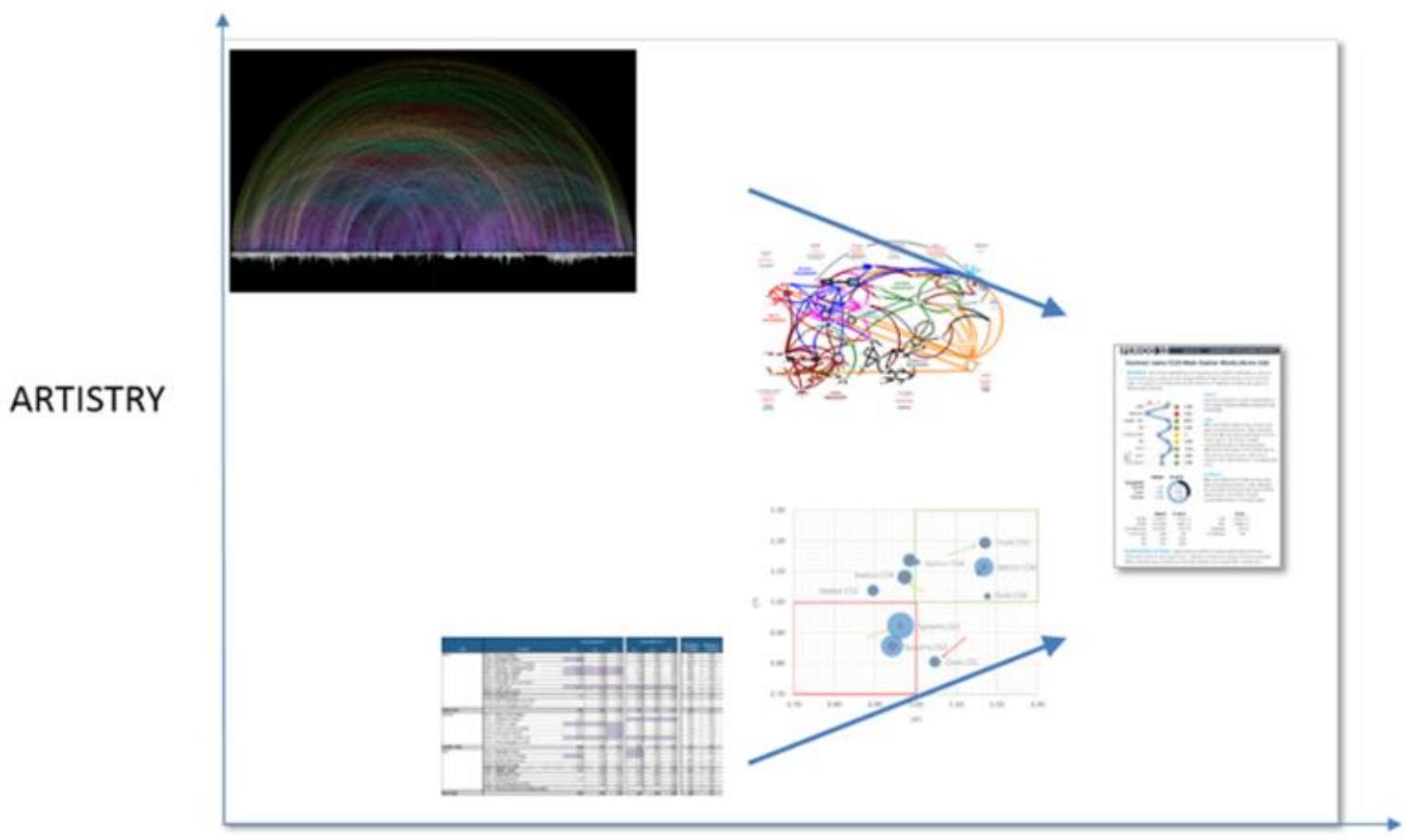

\section{BUSINESS VALUE}

Figure 1. Board Reporting, unpublished internal presentation (extract).

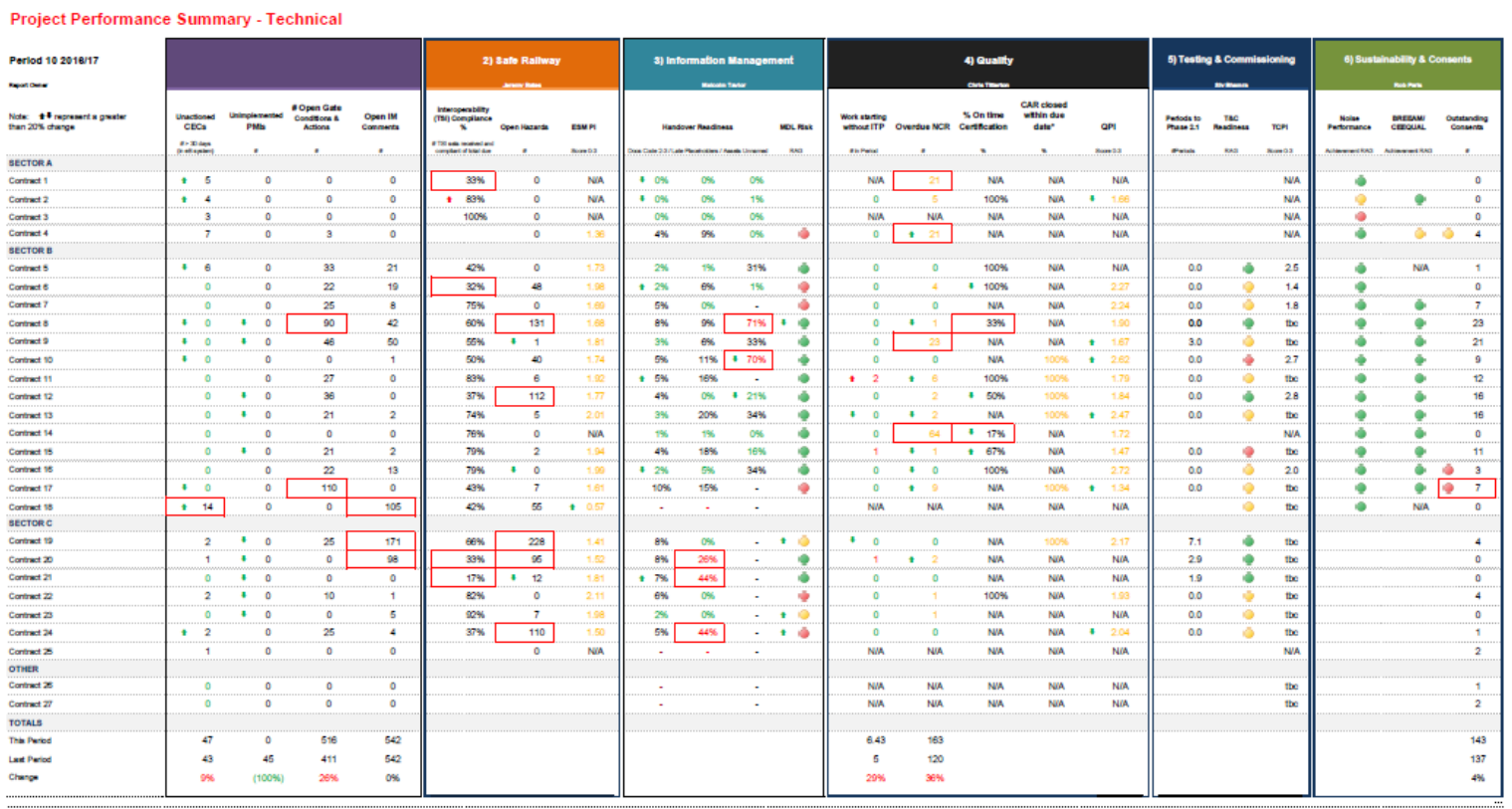

Figure 2. Technical dashboard (anonymized). 


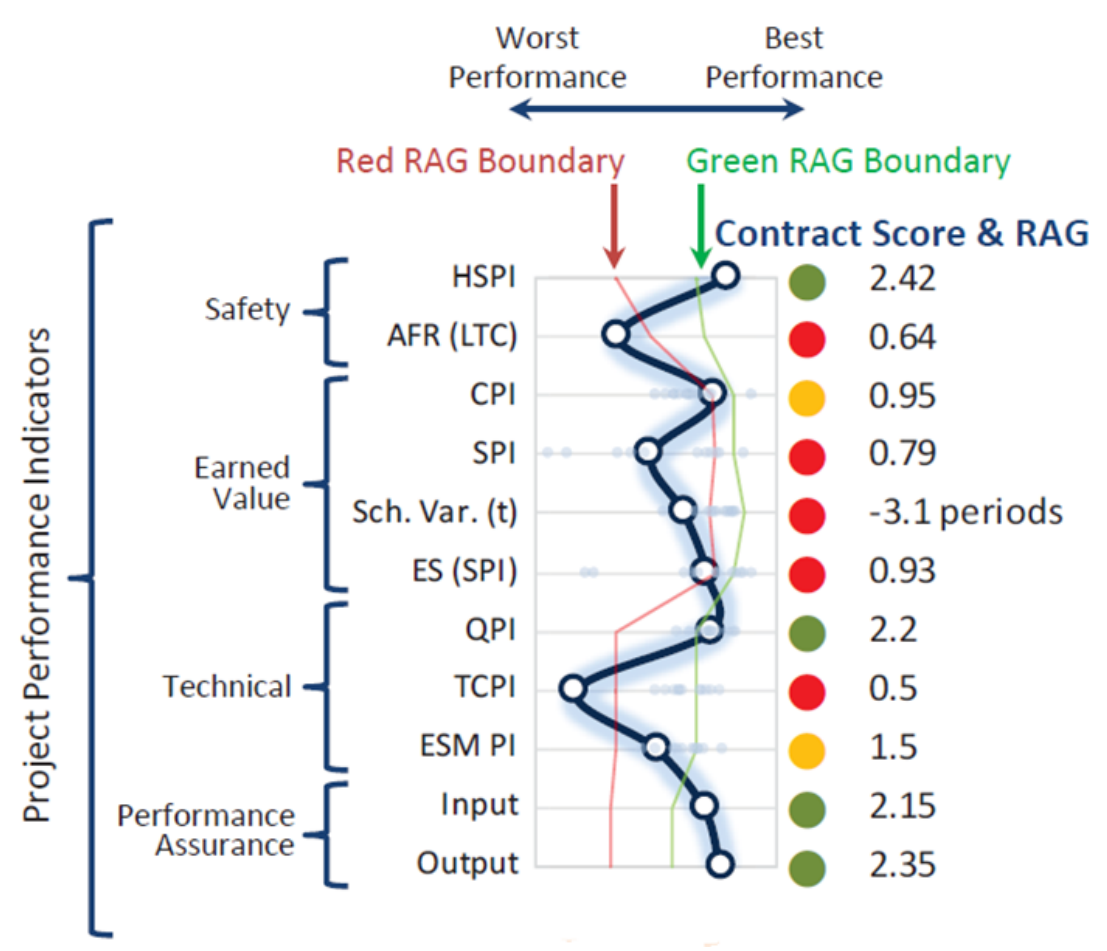

Figure 3. The worm diagram with an explanation of its value dimensions and features.

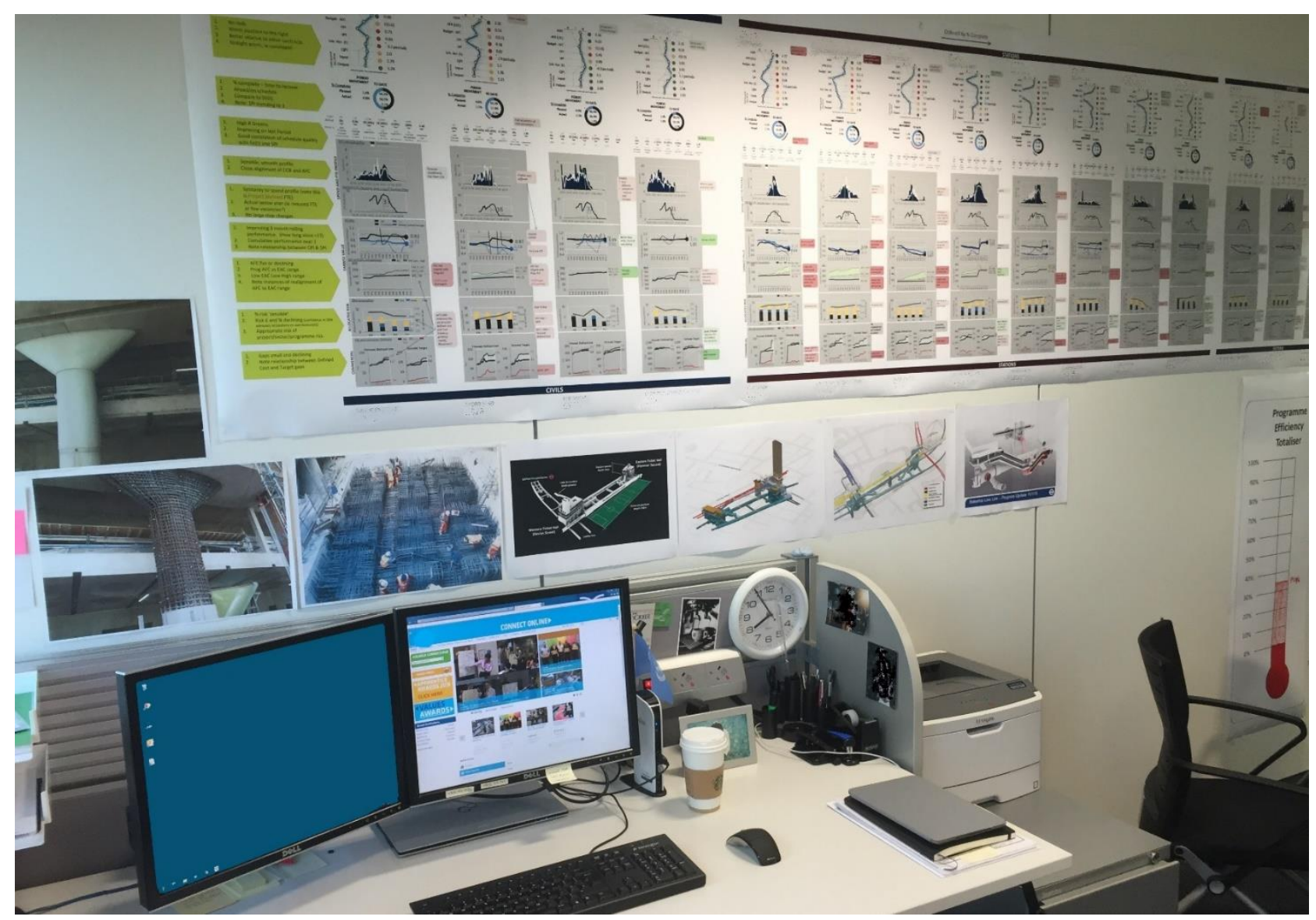

Figure 4. Office of the Director of Program Controls. Poster in the background (anonymized). 


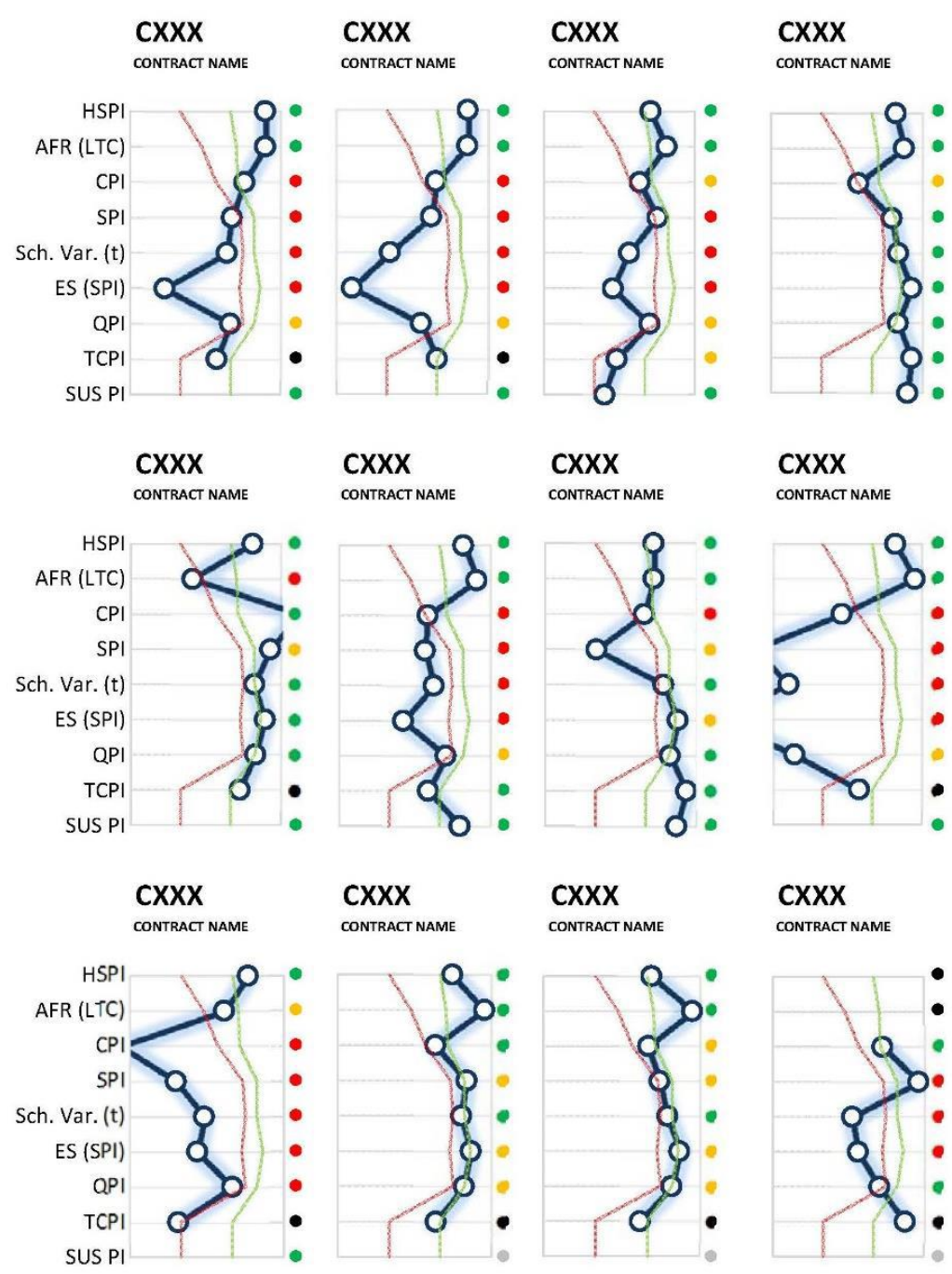

Figure 5. Project Performance summary in the Board Report (anonymized).
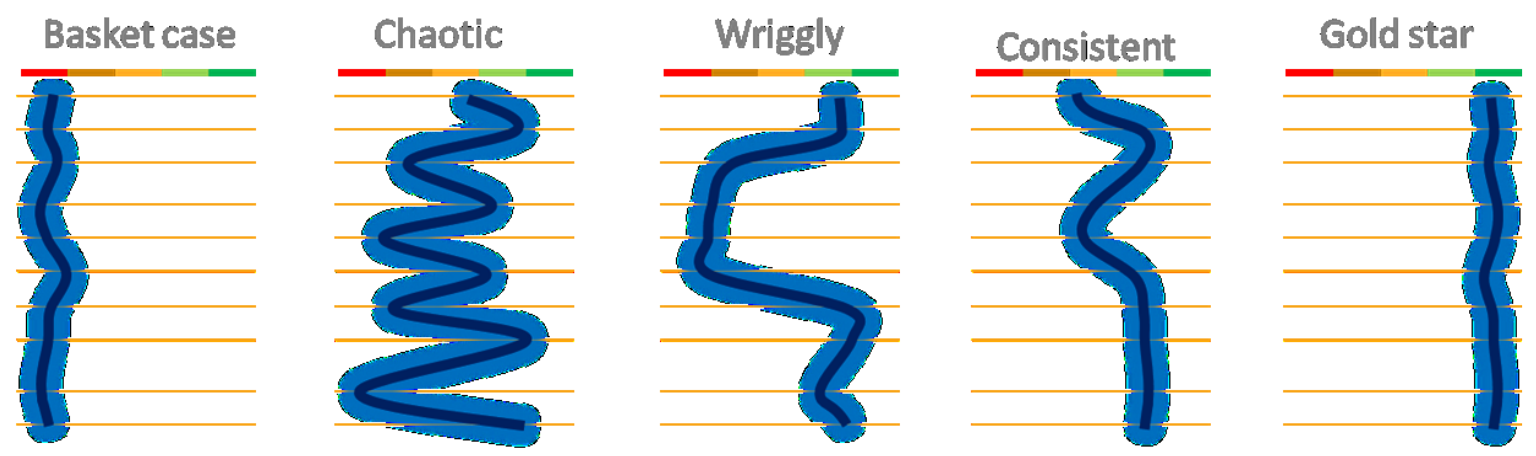

Figure 6. Board Reporting, unpublished internal presentation (extract). 